$$
\text { INEL/MISC-92065 }
$$

\title{
Pennsylvania Source Term Tracking System
}

\section{National Low-Level Waste Management Program}

\section{August 1992}


INET/MISC--92065

DE93 001935

\section{Pennsylvania Source Term Tracking System}

\section{August 1992}

\section{DISCLAIMER}

This report was prepared as an account of work sponsored by an agency of the United States Government. Neither the United States Government nor any agency thereof, nor any of their employees, makes any warranty, express or implied, or assumer any legal liability or responsibility for the accuracy, completeness, or usefulness of any information, apparatus, product, or process disclosed, or represents that its use would not infringe privately owned rights. Reference herein to any specific commercial product, process, or service by trade name, trademark, manufacturer, or otherwise does not necessarily constitute or imply its endorsement, recommendation, or favoring by the United States Government or any agency thereof. The views and opinions of authors expressed herein do not necessarily state or reflect those of the United States Government or any agency thereof.

\section{Idaho National Engineering Laboratory EG\&G Idaho, Inc. P.O. Box 1625 \\ Idaho Falls, ID 83415}




\section{CONTENTS}

1. Introduction $\ldots \ldots \ldots \ldots \ldots \ldots \ldots \ldots \ldots \ldots \ldots \ldots \ldots$

2. Installation and Setup $\ldots \ldots \ldots \ldots \ldots \ldots \ldots \ldots \ldots$

System Requirements $\ldots \ldots \ldots \ldots \ldots \ldots \ldots \ldots \ldots \ldots, 3$

Installing Tracking System Software $\ldots \ldots \ldots \ldots \ldots \ldots \ldots$

Data Lookup Tabies ....................... 4

Running the Software $\ldots \ldots \ldots \ldots \ldots \ldots \ldots \ldots$

3. Tracking System Overview $\ldots \ldots \ldots \ldots \ldots \ldots \ldots \ldots, 7$

Getting Started $\ldots \ldots \ldots \ldots \ldots \ldots \ldots \ldots \ldots \ldots \ldots$

Main Menu Options $\ldots \ldots \ldots \ldots \ldots \ldots \ldots \ldots \ldots \ldots$

PC Function Keys $\ldots \ldots \ldots \ldots \ldots \ldots \ldots \ldots \ldots \ldots$

4. Data Base Setup and Maintenance $\ldots \ldots \ldots \ldots \ldots \ldots \ldots$

Maintaining Generator Data $\ldots \ldots \ldots \ldots \ldots \ldots \ldots$

Add a New Generator . . . . . . . . . . . . . . . . 16

Change Existing Generator Records ............. 18

Delete Existing Generator Records . . . . . . . . . . . 19

Maintaining Lookup Tables .................. 20

Add an Entry to a Look , Data Table ........... 22

Change Existing Entries $\ldots \ldots \ldots \ldots \ldots \ldots \ldots \ldots \ldots 23$

Delete Existing Entries $\ldots \ldots \ldots \ldots \ldots \ldots \ldots \ldots 24$

State Maintenance Table .................... 25

Waste Stream Maintenance Table $\ldots \ldots \ldots \ldots \ldots \ldots 25$

Table Type Maintenance ................... 26

Radionuclide Maintenance Table ............. 26

Facility Maintenance Table ................. 27

Hazardous Constituent Maintenance Table . . . . . . . . . 27

Broker/Processor Maintenance Table . . . . . . . . . . 28

County Maintenance Table $\ldots \ldots \ldots \ldots \ldots \ldots \ldots 28$ 
5. Entering and Maintaining Survey Data $\ldots \ldots \ldots \ldots \ldots 29$

Add a Survey . . . . . . . . . . . . . . . 31

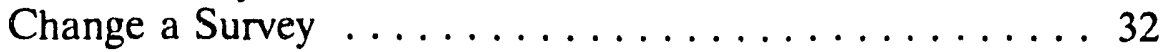

Delete is Survey ...................... 33

Print a Survey .................... 34

Table 1. Waste Shipped Directly to Disposal Site .... . . 35

Table 2. Waste Shipped Through Broker to Disposal Site . 37

Table 3. Mixed Waste Generated ............... 39

Table 4. Waste in Storage at End of Quarter ........ 41

Table 5. On-Site Volume Reduction or Processing .... . 43

Table 6B. Waste Shipped to Disposal Site this Quarter ... 45

Table 6A. Waste Shipped Off-Site for Processing ..... 48

6. Generating Reports $\ldots \ldots \ldots \ldots \ldots \ldots \ldots \ldots \ldots \ldots \ldots$

7. Backing Up Tracking System Data $\ldots \ldots \ldots \ldots \ldots \ldots \ldots 5$

Appendix A: Sample Reports . . . . . . . . . . . . 57 


\section{Introduction}

The Pennsylvania Source Term Tracking System tabulates surveys received from radioactive waste generators in the Commonwealth of Pennsylvania/Appalachian States Compact. Data on low-level radioactive waste is collected each quarter from generators using the Low-Level Radioactive Waste Management Quarterly Report Form (hereafter called the survey) and then entered into the tracking system data base. This personal computer-based tracking system can generate 12 types of tracking reports.

The first four sections of this reference manual supply complete instructions for installing and setting up the tracking system on a PC. Section 5 presents instructions for entering quarterly survey data, and Section 6 discusses generating reports. The appendix includes samples of each report. 


\section{Installation and Setup}

\section{System Requirements}

Running the Pennsylvania Source Term Tracking System requires the following:

- A personal computer (PC) with a minimum of 4.5 megabytes of random-access memory (RAM)

- A hard disk drive with a minimum of 8 megabytes of hard disk space for the data base and data base software, PC-DOS or MS-DOS, and the ORACLE tools. ORACLE tools require up to $12 \mathrm{MB}$ of additional disk space.

- A printer connected to the PC

- ORACLE 5.1C installed on the hard disk drive.

Note: The system has been designed for single user access. Access for the user ID MTM and password MTM must be set up in Oracle products SQL*Forms, SQL*Plus, and SQL*Report Writer. Consult your Oracle system administrator.

\section{Installing Tracking System Software}

1. Place the installation diskette containing the tracking system software in your floppy disk drive and secure the disk drive door.

2. At screen prompt $C_{:} \mid>$, type the letter of the floppy disk drive you are using (usually A:). Press ENTER.

3. Type INSTALL A: C: and press ENTER. This begins the automatic install procedure.

The software creates a subdirectory called ORACLE5|DBS|PASTS and installs the tracking system files in that directory. 
4. When installation is complete, type the letter of the hard disk drive

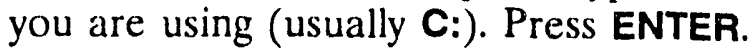

5. Ensure that ORACLE 5.1C is loaded on the hard disk drive.

6. Create a startup batch file that has the following commands:

\section{CD \ORACLE5\DBS\PASTS P01MN001}

Consult your PC's disk operating system instructions for creating batch files.

Note: You may add the ORACLE command as the first line of the batch file to automatically load Oracle. However, if Oracle is already loaded and the batch file tries to load it again, the batch file will abort.

7. To print reports, ensure that a printer is properly connected to the PC. Reports are configured to print on Epson printers.

\section{Data Lookup Tables}

The data lookup tables contain information used to verify survey entries and to make data entry easier, such as counties and states, radionuclides, and hazardous constituents. It may be necessary to enter some new data as surveys are being entered into the system, but much of the data is included on the diskette. Follow these instructions to automatically load the data into the system lookup tables.

1. To populate the lookup tables, it is first necessary to create a user ID MTM and password MTM in Oracle products SQL*Forms, SQL*Plus, and SQL*Report Writer. Consult your Oracle system administrator.

2. At the DOS prompt, type IMP MTM/MTM.

The example below shows the screen prompts that appear during the procedure. Follow the instructions shown in bold print. 
Import: Version 5.1.22.9 - Production on Thu May 14 11:13:39 1991

Copyright (c) 1987, Oracle Corporation, California, USA. All rights reserved.

Connected to: ORACLE V5.1.22.14 - Production

Import file: EXPDAT.DMP > TABLE.DMP

Enter insert buffer size (default is 10240, minimum is 4096) > (Press ENTER)

Export create by ORACLE version EXPROT:V05.01.22

List contents of import file only ( $\mathrm{Y} / \mathrm{N}$ ): $\mathrm{N}>$ (Press ENTER)

Ignore create errors due to object existence $(\mathrm{Y} / \mathrm{N})$ : $\mathrm{Y}>$ (Press ENTER)

Import the rows $(\mathrm{Y} / \mathrm{N})$ : $\mathrm{Y}>$ (Press ENTER)

Import of entire import file requested (Y/N): Y > (Press ENTER)

.Importing table "P01TB100" 50 rows imported

.Importing table "P01TB102" 7 rows imported

$\ldots$ and so on through the remaining tables.

\section{Running the Software}

1. To run the tracking system software, ensure that ORACLE 5.1C has been initiated on the PC (or add the ORACLE command to the batch file; see Step 6 above).

2. Run the batch file. The tracking system main menu displays on the screen. 


\section{Tracking System Overview}

The Pennsylvania Source Term Tracking System main menu appears when you log on to the software (consult your tracking system administrator for log-on instructions).

For ease of use, the tracking system structure parallels the Low-Level Radioactive Waste Management Quarterly Report Form. For each table on the survey there is a corresponding table data entry screen.

\section{Getting Started}

Several steps may need to be performed before entering survey data into the data base. Follow these three steps to make the data entry process more efficient.

1. If necessary, go through the surveys and change any curies to millicuries. Note: It is necessary to convert curies to millicuries only on surveys before 1991. All surveys from 1991 forward ask for data in millicuries.

Check the waste streams and assign them a two-digit code number (consult your tracking system coordinator for code number assignments).

2. Log on to the tracking system. At the main menu type 1 and press ENTER for Generator Data Maintenance, and enter generator information (see Adding a Generator, below).

3. At the main menu, type 4 and press ENTER for Lookup Table Maintenance, and enter hazardous constituents, waste streams, and broker/processor information (see Maintaining Lookup Tables, below).

Once the lookup table information is complete, begin entering the survey data (see Entering and Updating Survey Data, below). After several entry sessions the generator data and lookup tables will be fairly inclusive. Then it will not be necessary to update the lookup tables and generator data unless new generator or waste type information appears on the surveys. 


\section{Main Menu Options}

The main menu appears when you log on to the software.

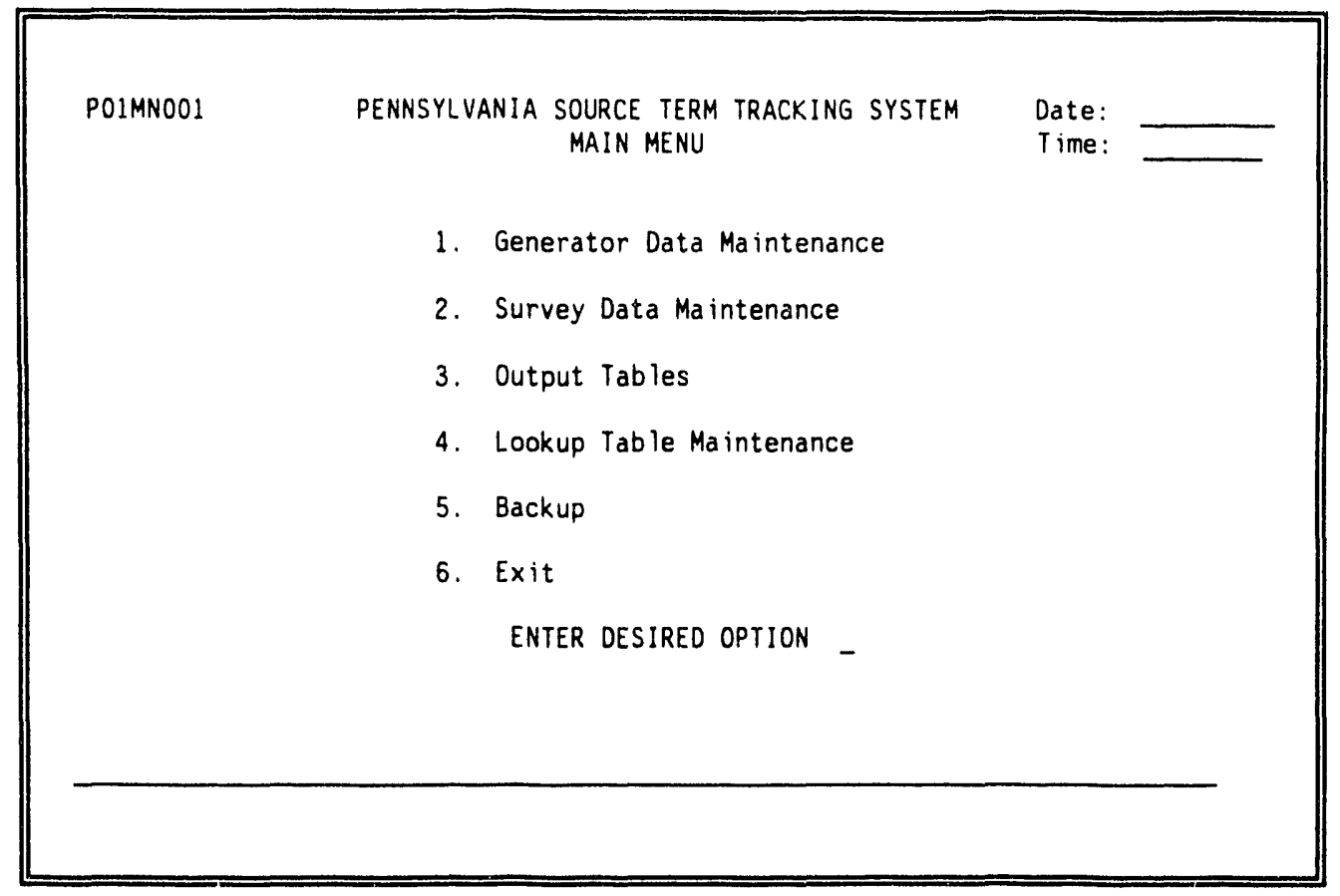

Figure 1. Pennsylvania Source Term Tracking System main menu

To choose an option, type the option number and press ENTER.

Note: Several steps may need to be performed before entering the survey data. See Getting Started, above.

The following entries describe the options available on the main menu.

1. Generator Data Maintenance

Enter specific data about each generator before entering the survey data. This information is located on the first page of the survey. 
2. Survey Data Maintenance

3. Output Tables

4. Lookup Table Maintenance

5. Backup

6. Exit
Use these entry screens to record the data found in Tables $1-6 \mathrm{~B}$ of the survey. Each data entry screen corresponds to a survey table.

Use this menu to select 12 types of reports to print.

Enter this data before entering the survey data. These tables contain general information common to all surveys, such as waste streams, radionuclides, facilities, hazardous constituents, and broker/processors. The system uses the tables to verify data entered for surveys.

Use this option to save the survey data to floppy disks after it has been entered into the tracking system.

Select this option to return to the DOS prompt. 


\section{PC Function Keys}

Function keys perform specific tasks throughout the system. Function key descriptions are presented at the bottom of each screen. The following function keys are available on the data entry screens.

Press $\mathbf{F} 1$ from any screen to display the PC function keys.

FUNCTION KEYS

Show function $F 1$

keys

Quit

F3

Main menu

F4

Clear entry

Shift-F4

Delete record F5

F5

Create record F6

Query

F7

Query

Clear record

Shift-F7

Displays lisı of function keys.

Clear record

Execute quer: $\quad F 8$ (begin search)

F8

Print

Shift-F8

Check lookup

F9

table

Return to DOS prompt.

Return to main menu screen.

Use to clear single entries on the multipleentry fields such as the nuclides and hazardous constituents on the lookup tables.

Deletes entire record (screen). Press F10 to verify the deletion.

Creates a blank record and begins entry-only mode. You cannot page down to new records until this record is either saved or deleted.

Begins search mode. Move cursor to entry field and type data to search for in that field. Note: The search data must exactly match the entries for that field. Press F8 to search.

Clears the entire record and begins search mode. You must use F7 or F8 to retrieve data after this command.

After typing search data into an entry field press F8 to begin the search.

You may press F8 without pressing F7 first to reset the records at the first record. Page down to see additional records.

Prints record on the screen.

Press F9 to access data lookup tables in a data entry field that corresponds to a table. Press TAB or ENTER to move through entries, and press Shift-F10 to select an entry. 
Commit

(save)

F10

from

lookup table
Save all data on screen. Notc: You must press F10 after every record to save changes. If you page up or down to a new record, the changes are not saved.

Shift-F10 Use to select an entry after pressing F9 to access the data lookup tables.

\section{CURSOR MOVEMENT}

Right

End of line

$\mathrm{Ctrl} \rightarrow$

Left

Beginning of $\mathrm{Ctrl}$ -

line

Next entry $\quad T A B$

field

Previous entry Shift-TAB

field

Next record $\quad$ PgDn, ।, or Ctrl-ENTER

Previous

PgUp, $\uparrow$, or Ctrl-Backspace

record

\section{EDITING FUNCTIONS}

Erase entry Ctrl-End

field

Exit/cancel ESC 


\section{Data Base Setup and Maintenance}

Two options on the main menu relate to entering and maintaining the general data base on the tracking system:

1. Generator Data Maintenance

4. Lookup Table Maintenance

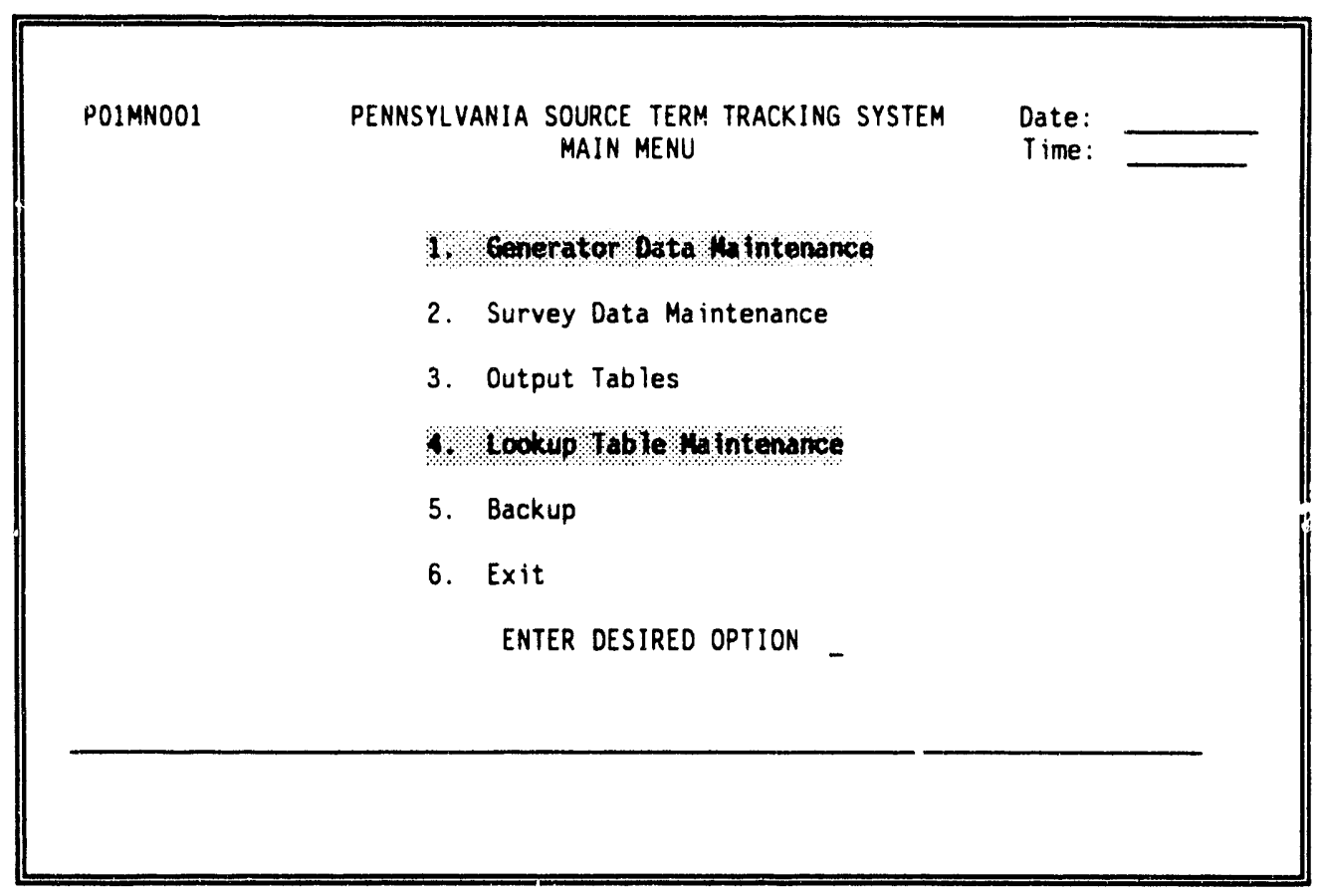

Figure 2. Pennsylvania Source Term Tracking System main menu 
Before entering the actual survey data, it is first necessary to enter the general information common to all the reports. If the generator information and lookup tables have not been recorded yet, follow these steps.

1. Log on to the tracking system. At the main menu typc 1 and press ENTER for Generator Data Maintenance, and enter generator information (see Adding a Generator, below).

2. At the main menu type 4 and press ENTER for Lookup Table Maintenance, and enter hazardous constituents, waste streams, and broker/processor information (see Maintaining Lookup Tables, below).

3. At the main menu type 2 and press ENTER for Survey Data Maintenance. Enter data from surveys.

If generator information and lookup tables have already bcen established, begin with main menu option 2, Survey Data Maintenance (see Entering and Updating Survey Data, below). 


\section{Maintaining Generator Data}

Before entering the survey data from the tables, enter the data for any generators that may not yet be recorded in the tracking system. The generator data information is found on the first page of the survey. If this data is already recorded in the tracking system, go on to the next section, Maintaining Lookup Tables.

To enter generator data, type 1 at the main menu (Figure 1) and press ENTER. The generator maintenance screen appears. From this screen you can add, change, or delete generator data.

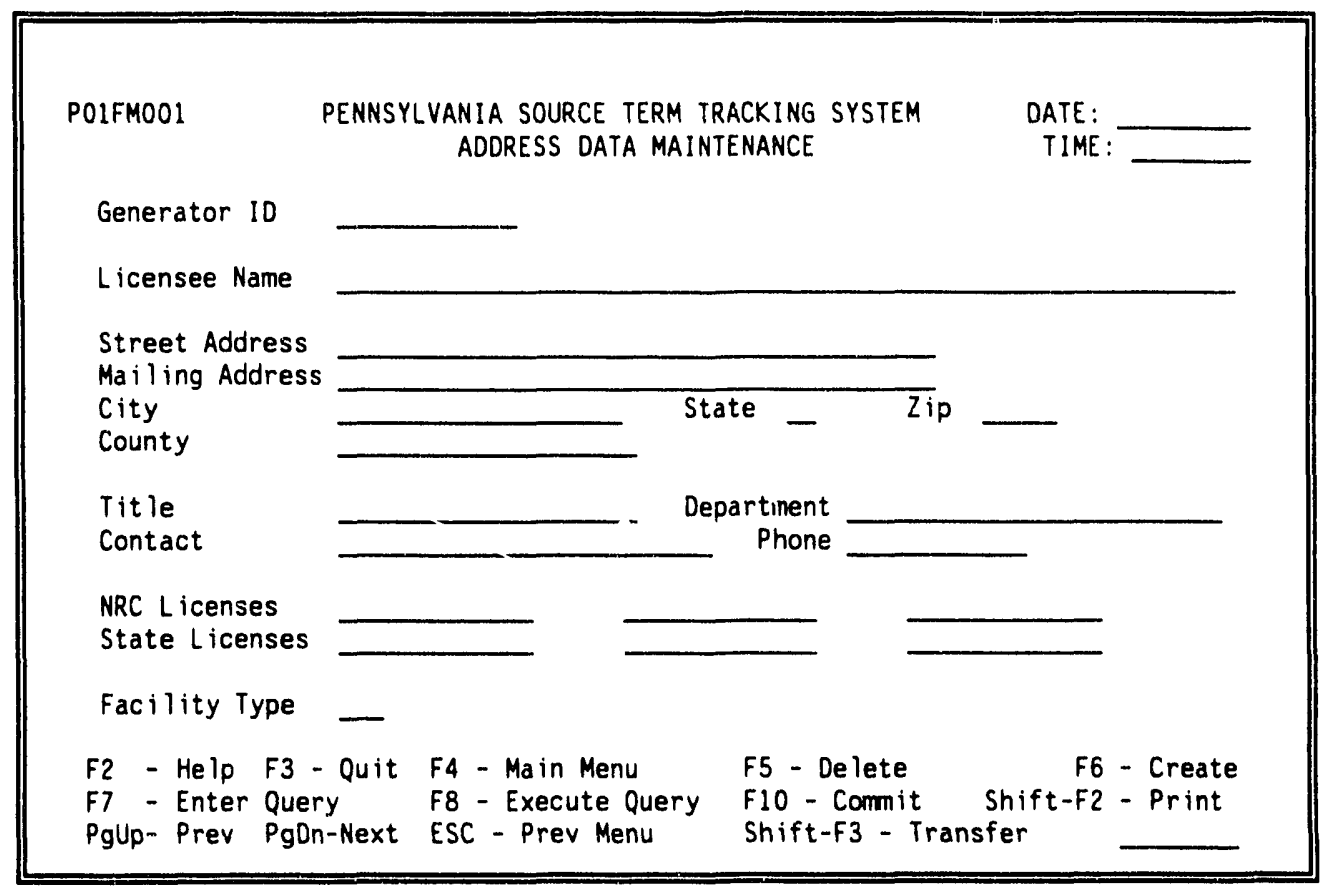

Figure 3. Generator maintenance screen

To search the data base to determine if data has already been entered for a particular generator, press F7 to enter search mode. Type the name of the generator, and then press $\mathbf{F 8}$ to begin the search. Another method is to PgDn through the generator records. 


\section{Add a New Generator}

1. To add a new generator to the data base, begin at the generator maintenance menu (Figure 3). Press F6 to add a new generator. This ciears the st i een (if data had been entered previously), begins the data entry mode, and places the cursor at the Generator ID field.

2. Enter the Generator ID. This is a unique alphanumeric identifier of up to 12 characters. Contact your tracking system coordinator for a list of the assigned generator IDs.

Note: All gencrator IDs must begin with state initials, such as PA.

3. TAB to move between fields, and fill in the remaining blanks. This specific generator information is located on the first page of the survey.

Note: You must fill in the County and Staic fields, Licenses (at least one), and Facility Type. The tracking system will not allow the record to be saved until this information is entered.

The tracking system can help locate the required information.

a. Place the cursor on the County, State, or Facility Type field and press $\mathbf{F 9}$ to search the general information recorded in the lookup tables.

b. Press TAB or ENTER to move forward through the entries. Press Shift-F10 to select the data.

4. Press $\mathbf{F 1 0}$ to save the record. Note: If $\mathbf{F 1 0}$ is not pressed before paging up or down to a new record, the changes will be lost. 


\section{Error Messages:}

"Row has already been inserted." Indicates that another record has the same name/generator ID.

"Record must be entered or deleted first." Indicates that you are in the F6 data entry mode. You must either save the record with F10 or delete the record with Fs before the system will move to the next record.

"Oracle error occurred while trying to ..." Indicates a problem with the system setup. Contact your tracking system administrator. 


\section{Change Existing Generator Records}

1. To change existing generator records, begin at the generator maintenance menu (Figure 3). To locate the record to change, three search methods are available. F7 searche or a specific data entry. $\mathbf{F 8}$ lists all records in order of generator ID. FS uses lookup tables to narrow the search.

\section{F7, Specific Data Search}

a. Press F7 to begin the search mode. The data entry screen clears and the cursor moves to the top of the screen.

b. TAB to a data entry field and type in the specific data you are searching for, such as the licensee name or generator ID.

c. Press F8 to execute the search.

If the data field you searched has more than one record with the same information, (such as all generators in a particular county) press PgDn to move down through the records.

d. Press F7 again to clear previous search parameters and begin a new search.

Note: Several search parameters can be entered at the same time to narrow the seaich, such as County and Facility Type. Only records that match both parameters will be retrieved.

\section{F8, General Search}

Press $\mathbf{F 8}$ from anywhere on the generator maintenance screen. The tracking system displays the first generator record, ordered alphabetically by Generator ID. Press PgDn to move to the next generator record.

\section{F9, Lookup Tables Search}

a. Press F7 to begin search. Place the cursor in the State, County, or Facility field and Press F9. The lookup table data is displayed in the field. 
b. Press TAB or ENTER to scroll through the entries.

c. Press Shift-F10 to select an entry.

d. Press F8 to begin a search of all generator data that includes the selected entry. The screen clisplays generators for the selected entry in alphabetical order. Press PyDn to view the next generator record with the selected entry.

2. After locating the record to change, TAB through the fields. Type over existing data, delete existing data with the DEL key, or clear the entry with Ctrl-End and enter new data.

Note: Use Shift-F4 to clear a single entry or Shift-F7 to clear the record (the screen). This will not delete changes that have already been saved.

3. Press F10 to save the changed record. The screen prompts, "Do you want to commit the changes you have made?" Press F10 again to save the changes or press Shift-F7 to save the original record, blank the screen, and begin a new search.

\section{Delete Existing Generator Records}

To delete existing records, use the search methods described above (F7, F8, F9) to locate the desired record. Press F5 to delete the record. A screen prompt asks you to press F10 again to verify the deletion. After verification, the record is deleted and the next record is displayed. 


\section{Maintaining Lookup Tables}

To work with the data lookup tables, type 4, Lookup Table Maintenance, at the main menu (Figure 1) and press ENTER. The maintenance menu for the lookup tables appears. Type the number of the desired lookup table (1-8) and press ENTER.

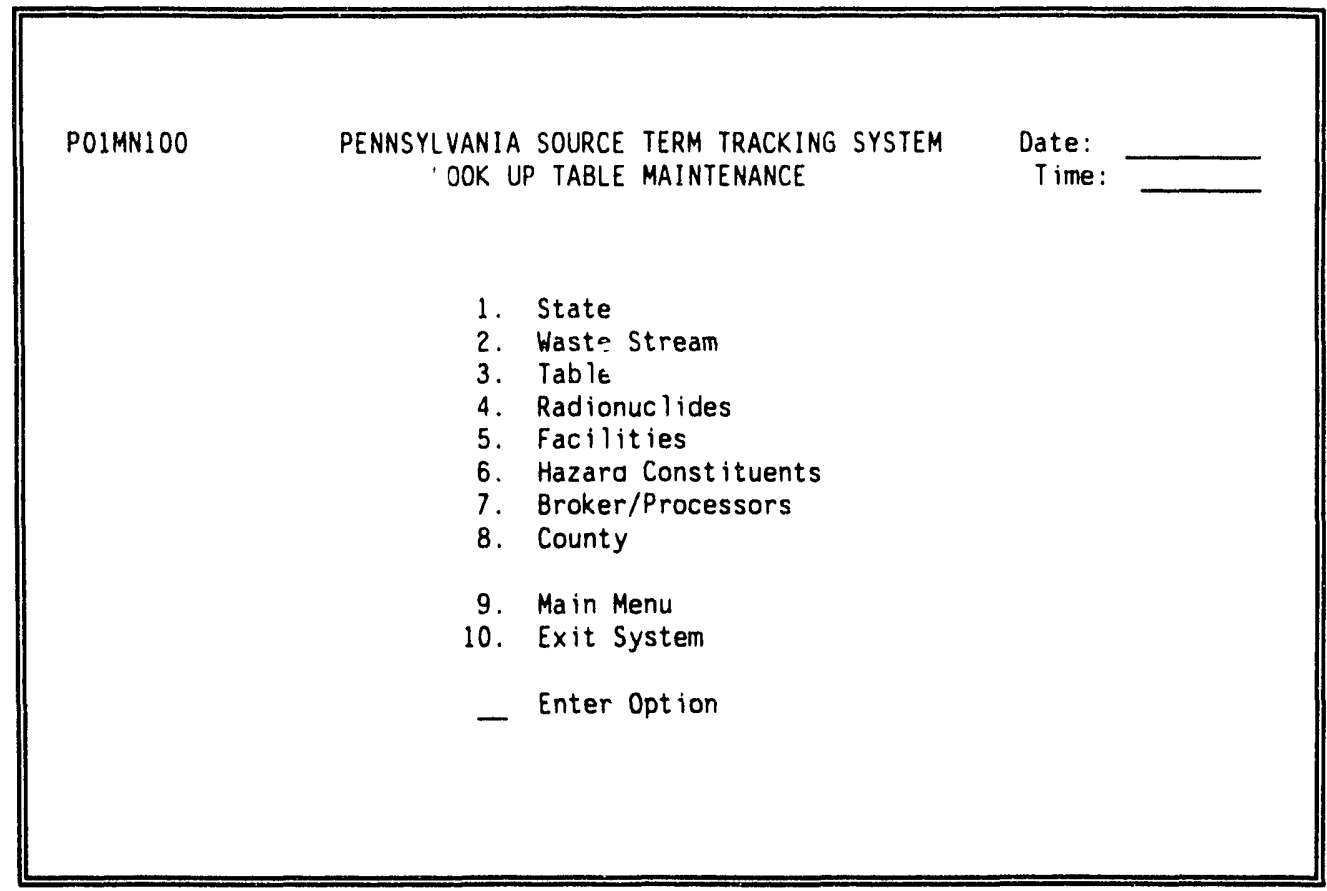

Figure 4. Lookup table maintenance menu

Note: Before entering the actual data from the survey, it is first necessary to enter the general information common to all the reports in the lookup tables. These data need only be entered once. After several entry sessions this information will already be recorded in the lookup table data base and you can immediately begin entering the survey data. If the lookup tables are complete, go on to the next section, Entering and Maintaining Survey Data.

The installation diskette includ . data for all the lookup tables, but it may be necessary to enter additional : srmation to complete the lookup tables. 
Consult your tracking system coordinator for codes to assign to waste streams and broker/processors.

The following ertries describe the options available on the lookup table maintenance manu.

1. State

2. Waste Stream

3. Table

4. Radionuclides

5. Facilities

6. Hazardous Constituents

7. Broker/processors

8. County
Lists all 50 states and assigns a two-digit alphabetic code corresponding with U.S. Postal Service codes (i.e., the code for Pennsylvania is PA). These codes are included on the installation diskette. It is not necessary to add, change, or delete these codes.

Lists generator waste streams and assigns a two-digit numeric code provided with the surveys.

Lists the survey data entry screens that correspond to the seven tables in the survey. These tables cannot be added, changed, or deleted without programming support.

Lists the radionuclides found in the generator waste streams. 311 nuclides are included on the installation diskette, but it may be necessary to add radionuclides occasionally.

Lists categories of facilities and assigr:s a threedigit alphanumeric code that corresponds with tine categories on the first page of the survey.

Lists the hazardous constituents found in the generator waste streams.

Lists broker and processor data, including the two-digit ID, type, address, and phone number.

Lists all counties that contain generators who participate in this survey. 
Several rules apply to all the lookup data tables.

1. New entries can be added to the tables, bu in entry cannot be deleted if a survey record in the data base still includis that entry.

2. Entries must be added to the lookup tables before they can be entered on the survey entry screens.

3. Lookup tables can be accessed on most screens by moving the cursor to the data entry field corresponding to a lookup table and pressing F9. The entries for that lookup table are presented in the data entry field in alphanumeric order. Press TAB or ENTER to scroll forward through the entries. Press Shift-F10 to select an entry.

4. Use $\downarrow$ and $\uparrow$ to scroll through data lists in the lookup tables.

\section{Add an Entry to a Lookup Data Table}

1. From the lookup table maintenance menu (Figure 4), type the number of the desired lookup table (1-8) and press ENTER.

2. Press $\mathbf{F 6}$ from anywhere in the lookup table to add an entry to the table. Enter the appropriate information, and press F10 to save the data. 


\section{Change Existing Entries}

1. From the lookup table maintenance menu (Figure 4), type the number of the desired lookup table (1-8) and press ENTER.

2. Locate the entry to change. Two search methods are available. F7 searches for a specific data entry, and PgDn pages through the entries in alphanumeric order.

a. To search for a specific entry, place the cursor in any field and press F7 to begin the search mode. The screen clears. Type the specific data you are searching for, such as the county or waste type. Press F8 to execute the search.

b. To conduct a general search, press F8 to reset the records. Press PgDn or $\downarrow$ to move through the entries.

3. Press $\downarrow$ to move through the entries. Type over existing data, delete existing data with the DEL key, or clear the entry with Ctrl-End and enter new data.

Note: Use Shift-F4 to clear a single entry or Shift-F7 to clear the record (the screen). This will not delete changes that have already been saved.

4. Press F10 to save the changes.

Note: If the error message "Field is protected against update" appears, this entry is still being used by a survey record in the data base and it cannot be changed or deleted. 


\section{Delete Existing Entries}

Note that a lookup table entry cannot be changed or deleted if a survey record in the data base still includes that entry.

1. Locate the entry to delete. wo search methods are available. F7 searches for a specific data entry, and PgDn pages through the entries in alphanumeric order.

a. To search for a specific entry, place the cursor in any field and press F7 to begin the search mode. The screen clears. Type the specific data you are searching for, such as the county or waste type. Press F8 to execute the search.

b. To conduct a general search, press F8 to reset the records. Press PgDn or $\downarrow$ to move through the entries.

2. Press F5 to delete the record. The screen prompts you to press F10 to verify the deletion.

Note: If the error message "Field is protected against update" appears, this entry is still being used by a survey record and it cannot be changed or deleted.

The following pages show the lookup table maintenance screens. 


\section{State Maintenance Table}

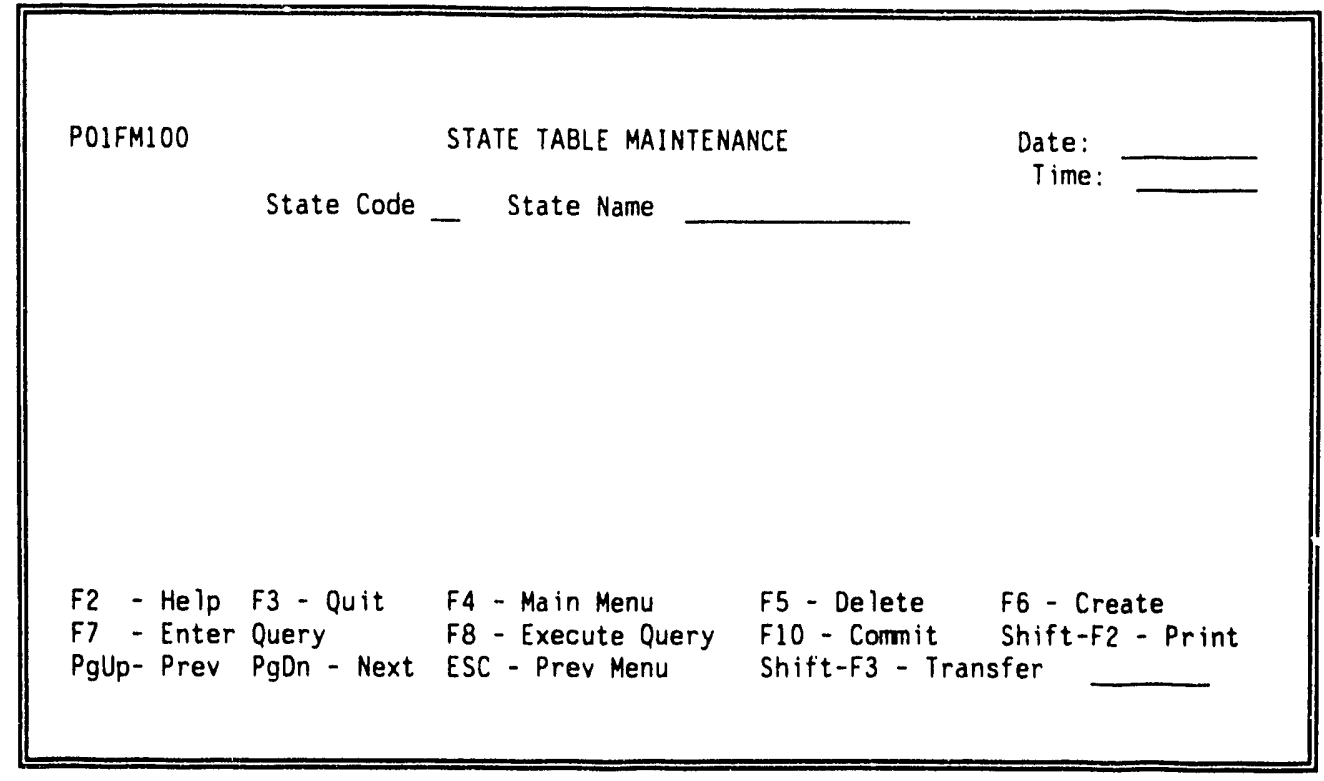

Figure 5. Maintenance table for states

\section{Waste Stream Maintenance Table}

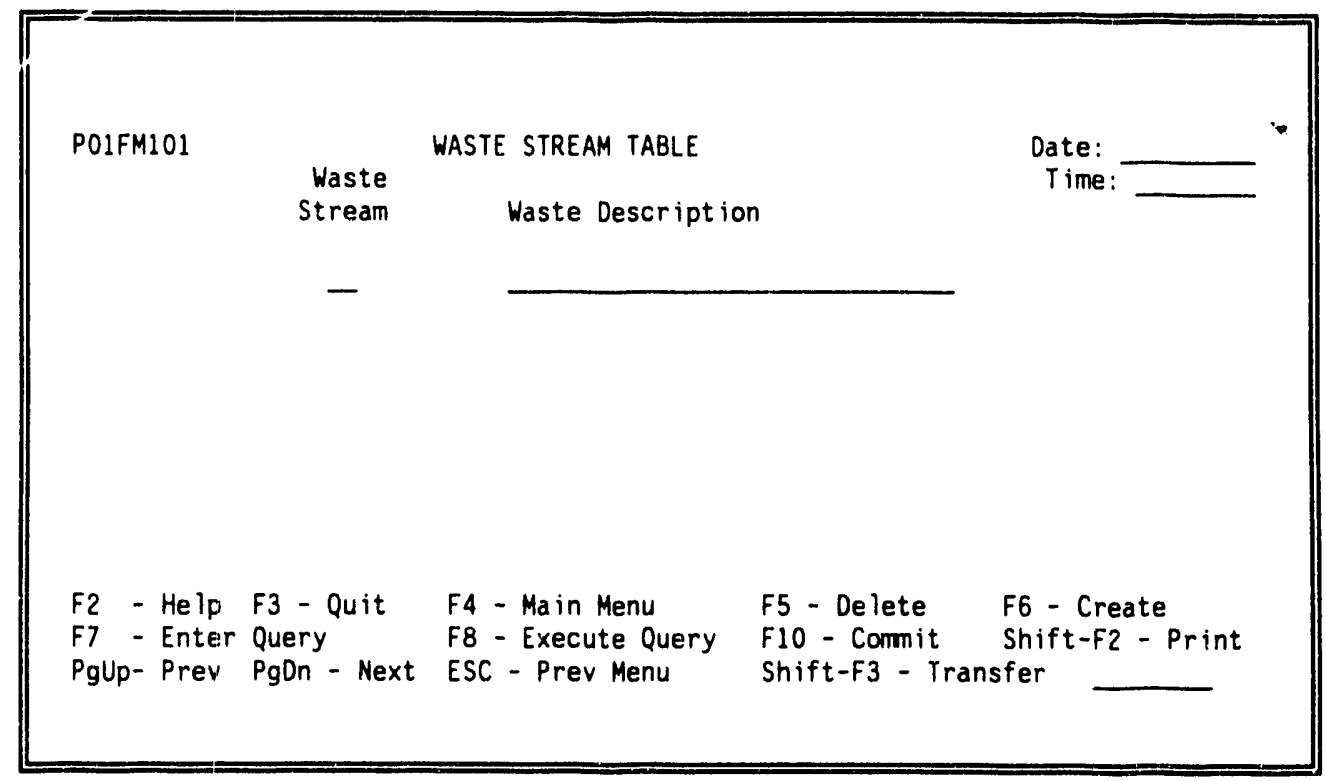

Figure 6. Maintenance table for waste streams 
Table Type Maintenance

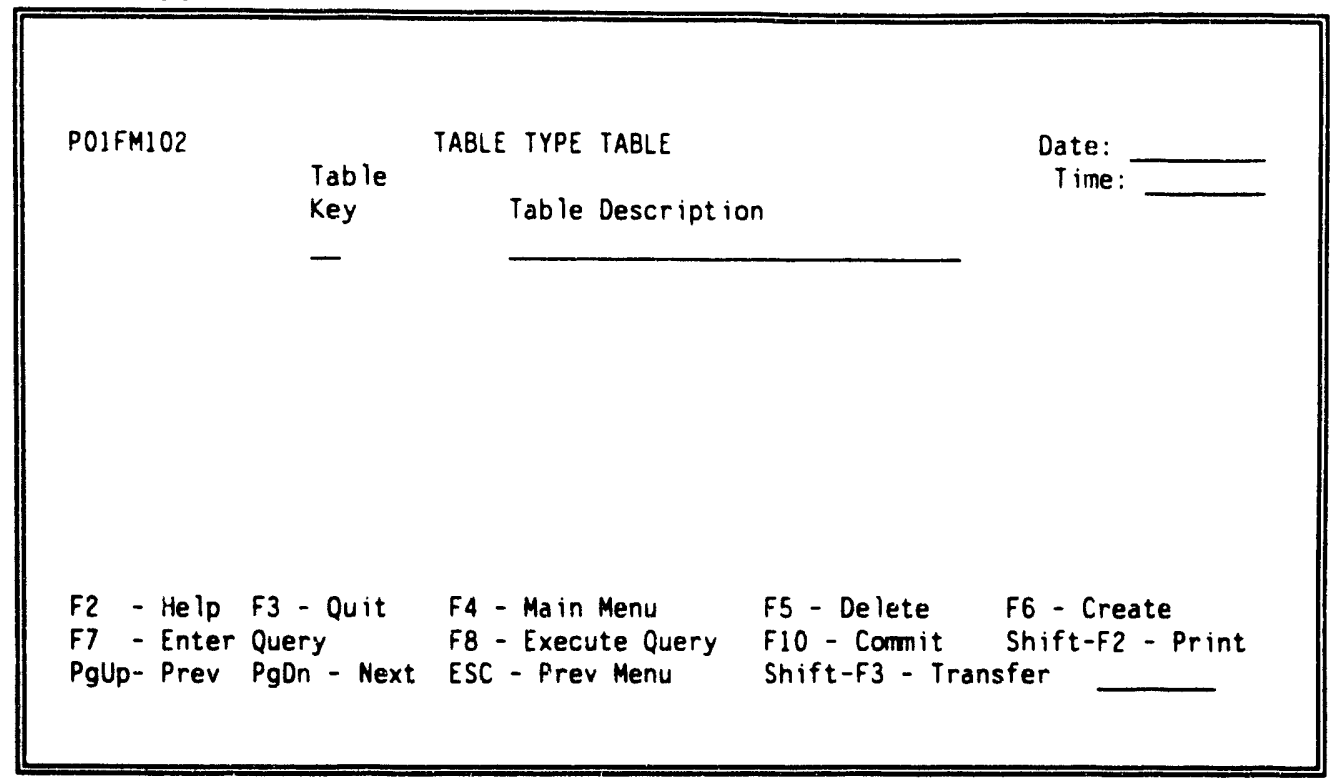

Figure 7. Maintenance table for table types

\section{Radionuclide Maintenance Table}

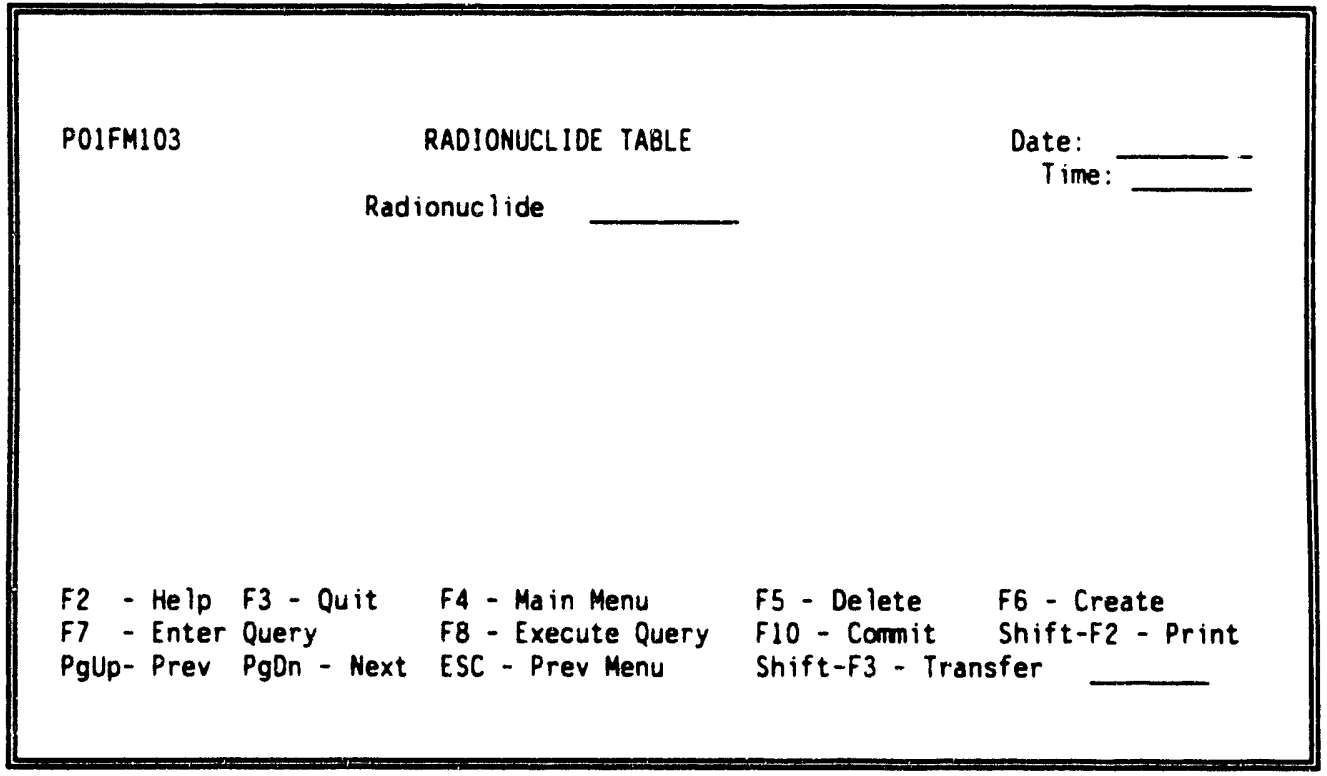

Figure 8. Maintenance table for radionuclides 


\section{Facility Maintenance Table}

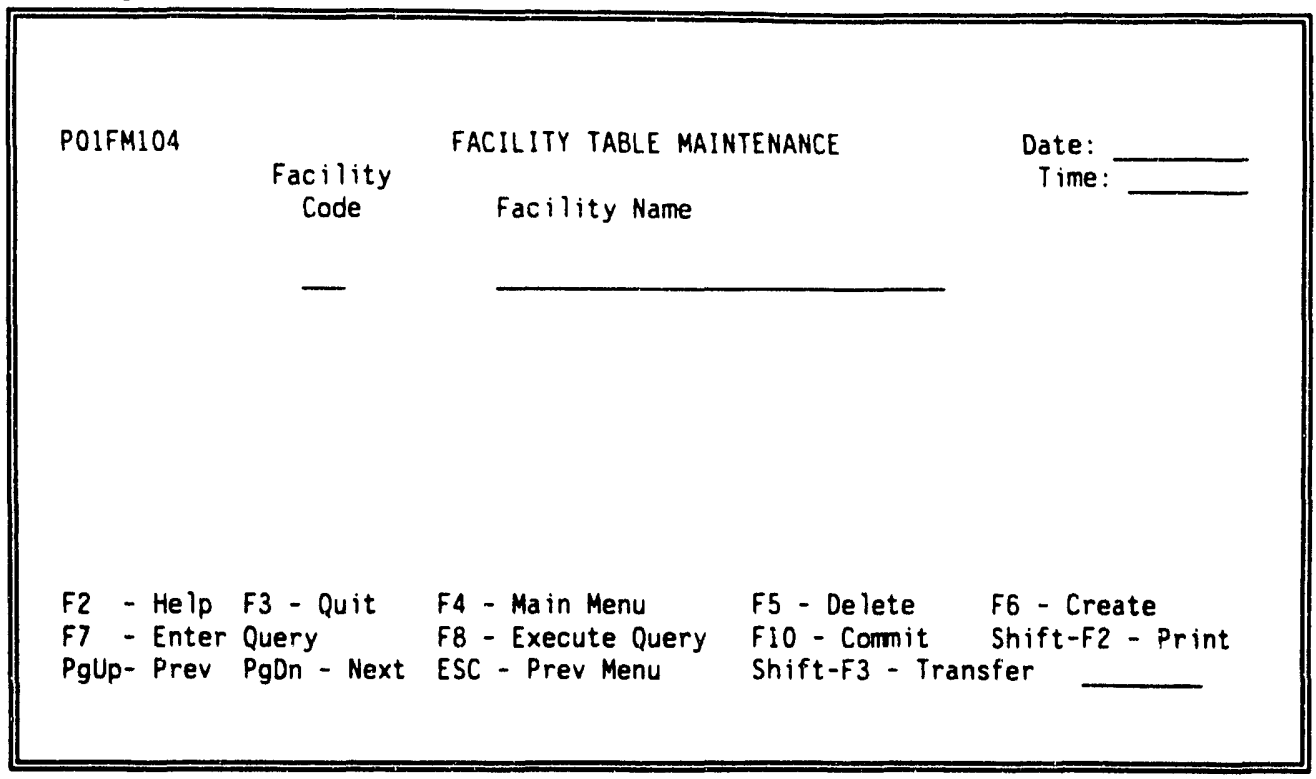

Table 9. Maintenance table for facility types

\section{Hazardous Constituent Maintenance Table}

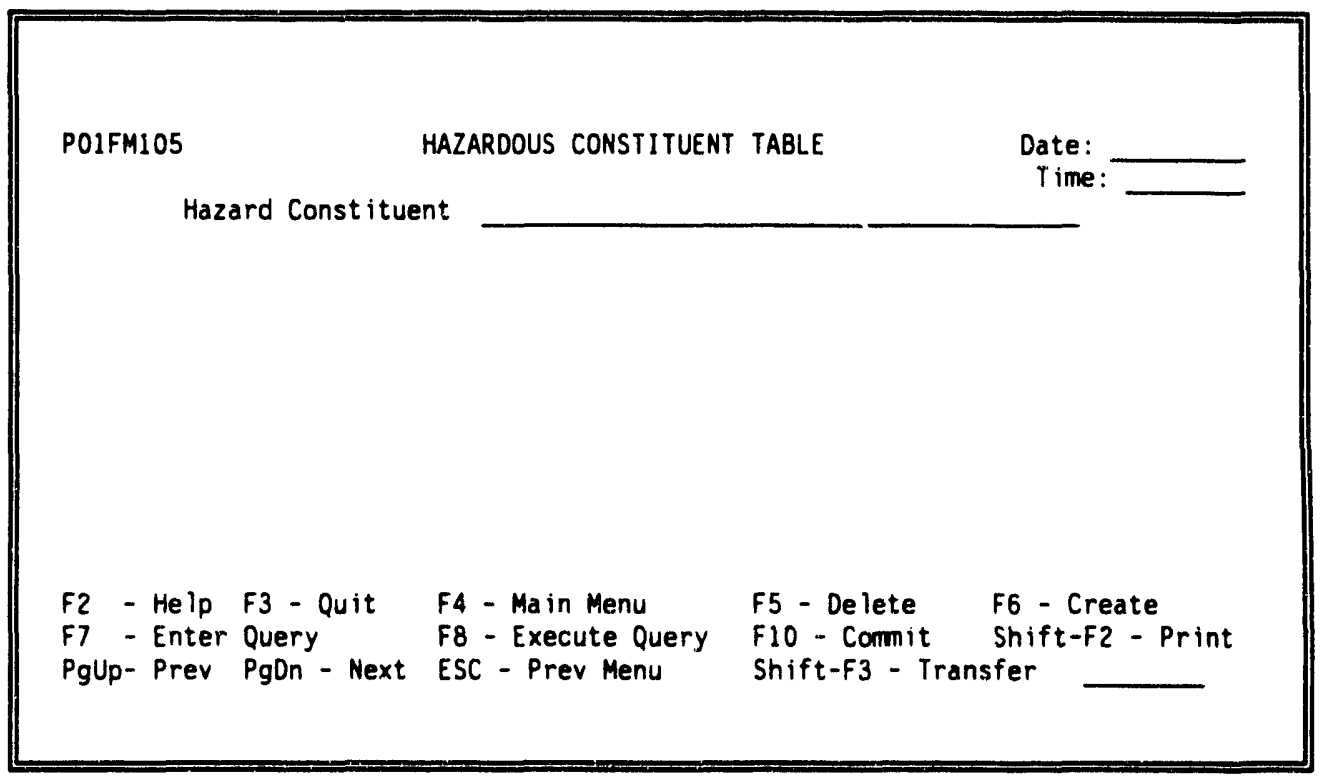

Figure 10. Maintenance table for hazardous constituents 


\section{Broker/Processor Maintenance Table}

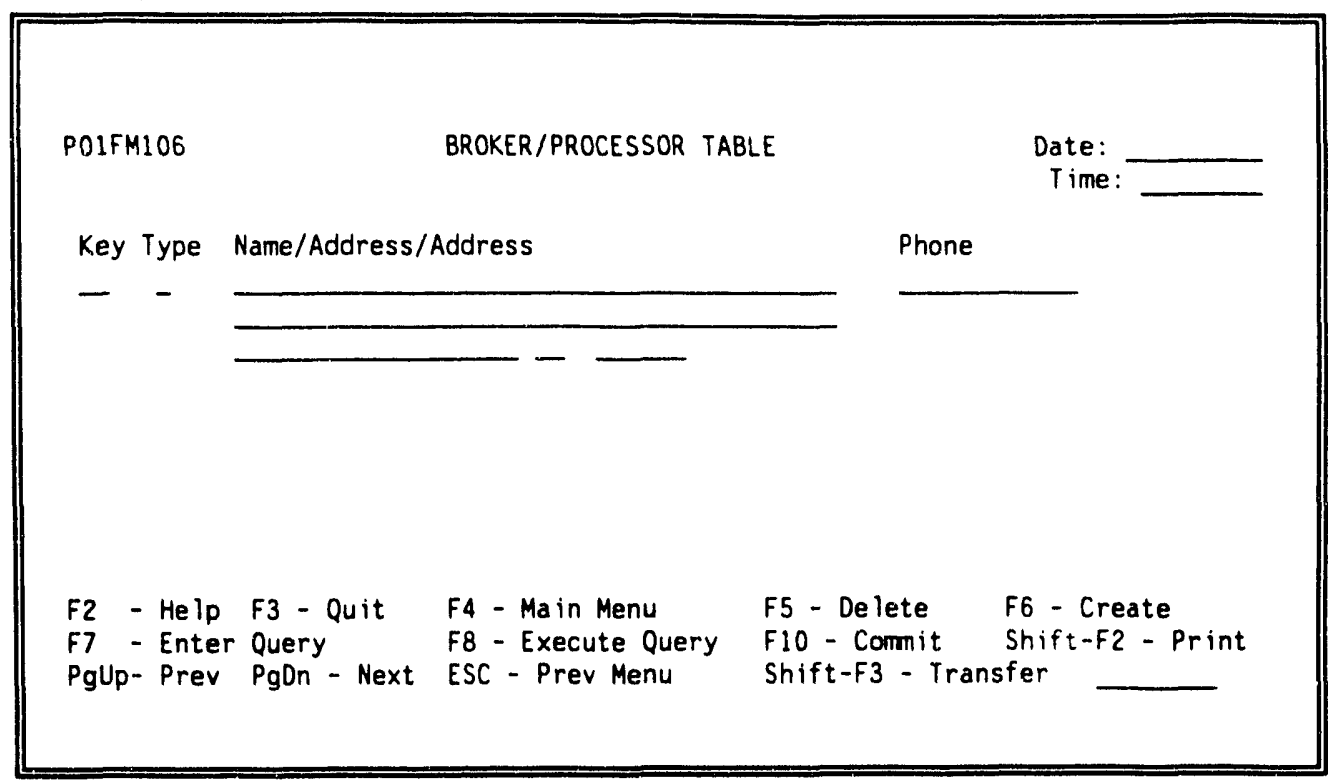

Figure 11. Maintenance table for brokers and processors

\section{County Maintenance Table}

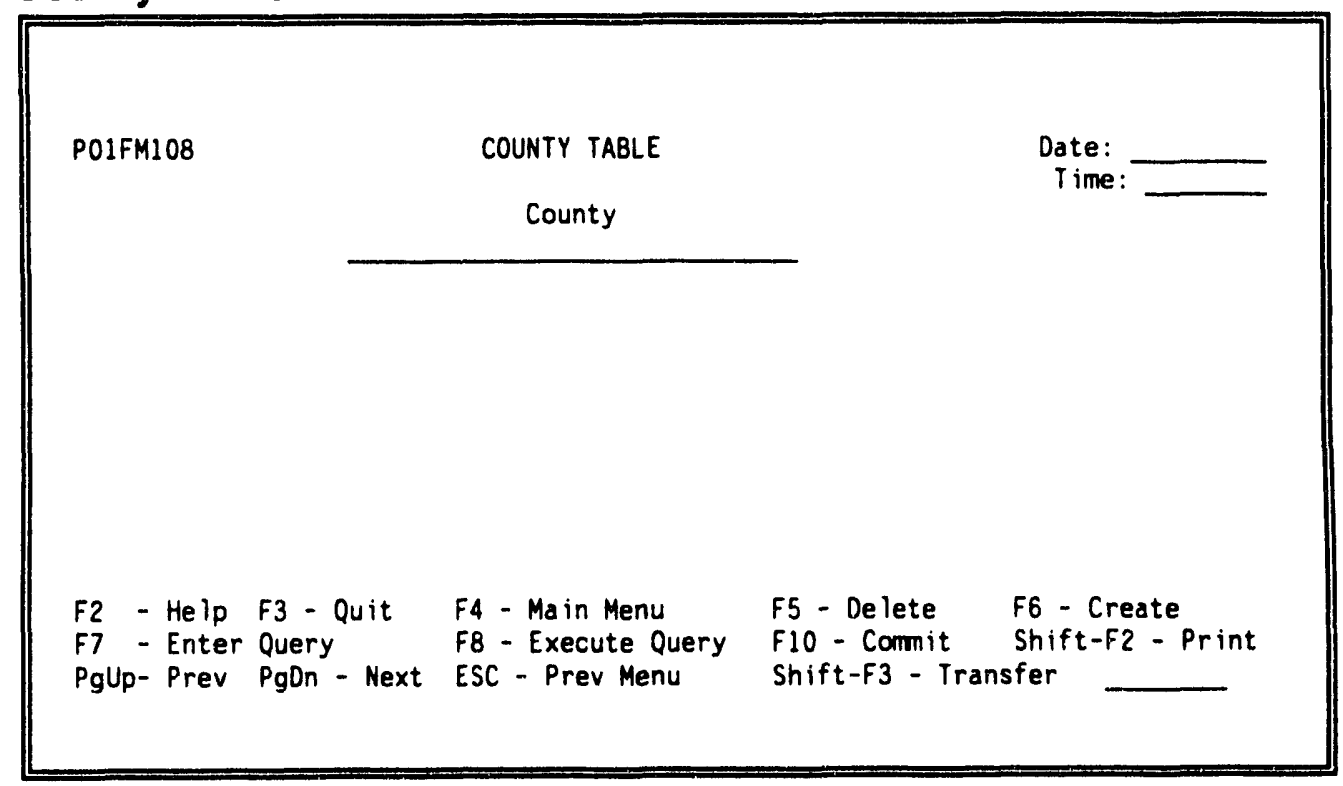

Figure 12. Maintenance table for counties 


\section{Entering and Maintaining Survey Data}

To add, change, delete, or print a generator survey, type 2, Survey Data Maintenance, at the main menu (Figure 1) and press ENTER. The survey entry menu appears.

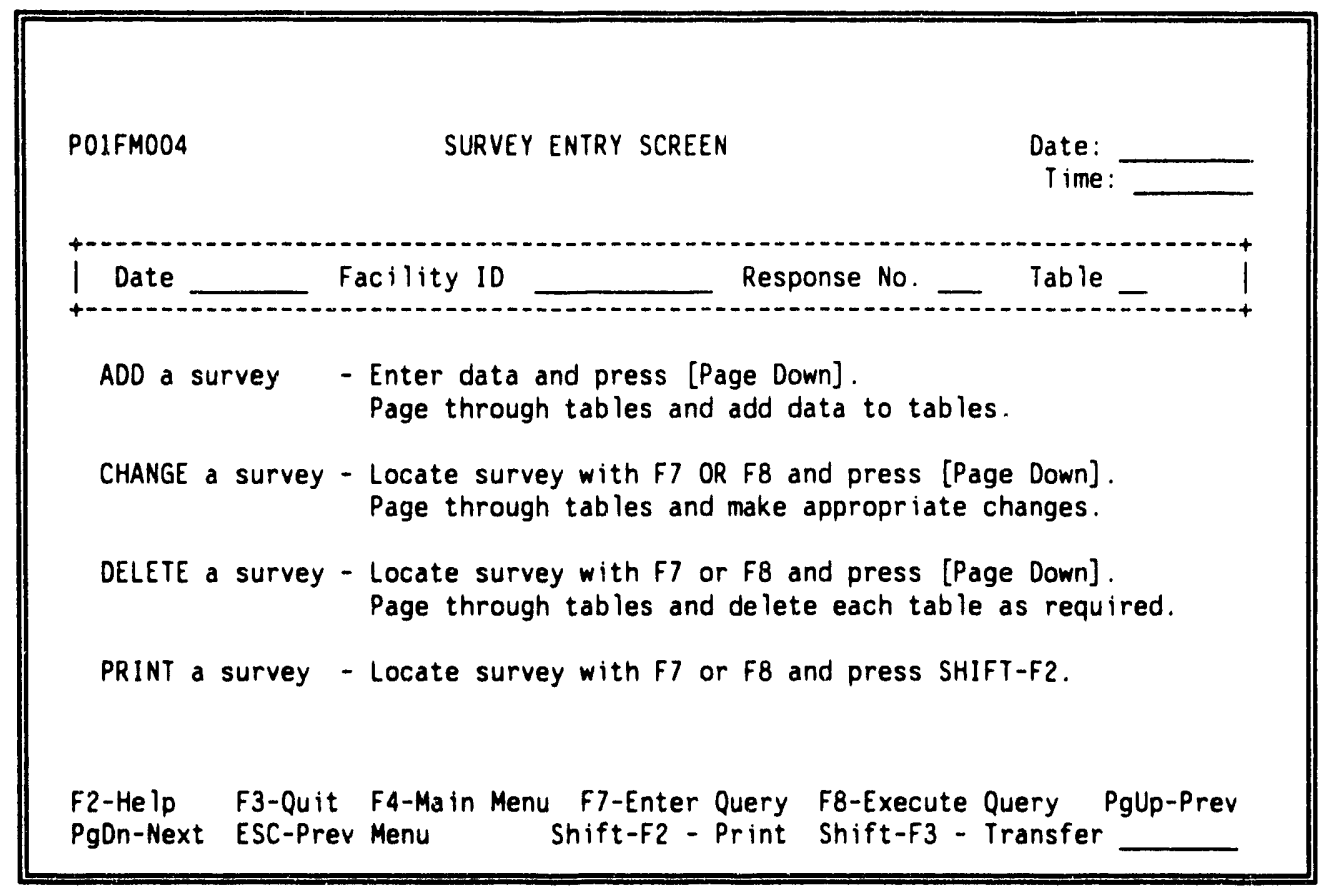

Figure 13. Survey entry menu

Data on low-level radioactive waste is collected each quarter from generators using the survey and then entered using these screens. Each of the survey entry screens corresponds with a table on the generator survey. 
Note: It may be necessary to perform a few additional steps before beginning the data entry for generator surveys:

1. Ensure that all data for the gencrators in the surveys have been added (sec Add a New Generator, al: 'e).

2. Ensure that all data have been entered for the lookup tables, such as waste streams, radionuclides, facilities, and broker/processor information (see Maintaining Lookup Tables, above).

3. If necessary, go through the quarterly reports and change any curies to millicuries. Note: It is necessary to convert curies to millicuries only on surveys before 1991. All surveys from 1991 forward ask for data in millicuries.

Check the waste streams and assign them a code number (consult your tracking system administrator for waste stream code numbers). 


\section{Add a Survey}

1. To add a survey, begin at the survey entry menu (Figure 13). Enter the Date of the survey, the Facility ID (generator ID), and Response No. at the top of the first survey entry screen. These three data entry fields must be filled.

a. To determine the Facility ID, use F9 to scan through the current generator IDs. Move the cursor to the Facility ID field, and press F9. Press TAB or ENTER to scroll through the list of current generator IDs. To select a generator ID, press Shift-F10.

b. If a generator ID has not been assigned, type 1 (Generator Data Maintenance) and press ENTER at the main menu (Figure 1), assign the generator a unique ID, and add the generator information (see Add a New Generator, above).

c. Enter 1 for the Response No., unless the survey contains duplicate entries in a table. If a table has two or more entries with the same waste stream and waste class, enter 2,3 , etc. for the Response No. for each entry provided.

2. Press PgDn to move to Table 1, waste shipped directly to disposal sites.

3. Press $\mathbf{F} \mathbf{6}$ to begin data entry mode. Enter the data from Table 1 of the survey into Table 1 of the survey entry screens. Press F10 to save the data on that screen before moving to the next screen.

4. Continue pressing PgDn and entering data until all seven tables have been entered on the survey entry screens. Remember to press F10 after each screen is entered to save the data. Each of the survey entry screens is explained in detail below.

\section{Error Messages:}

"Incorrect State" indicates that the generator ID is improperly assigned on the generator data screen. Press F4 to return to the main menu. Type 1 and press ENTER for Generator Data Maintenance, and check the generator ID to ensure it begins with state initials.

"Query caused no records to be retricved" indicates that the system is in search mode instead of data entry mode. Press F6 or ESC to return to data entry mode. 


\section{Change a Survey}

1. To change an existing survey, begin at the survey entry menu (Figure 13). Press F7 to begin search mode. Enter the Date of the survey, the Facility ID (generator ID), and Response No. at the top of the first survey entry screen. These three data entry fields must be filled.

2. Press $\mathbf{F 8}$ to begin the search for the specified Date and Facility ID.

- If the Facility ID is unknown, use F9 to scan through the current generator IDs. Move the cursor to the Facility ID field, and press F9. Press TAB or ENTER to scroll through the list of current generator IDs. To select a generator ID, press Shift-F10.

- If the date is unknown, select a generator ID and then press $\downarrow$ to page through all the records for that generator ID. The Date field updates as each new set of records is reached.

Note: It may take some time to move through lengthy records. To check if the tracking system is actually paging through records as you press $\downarrow$, note the counter at the bottom right of the screen. If the counter is moving, the system is scrolling through records.

- If the Date, Facility ID, and Response No. are not known, press F8 instead of pressing F7 in Step 1. This resets the records to the first alphabetically listed generator and the earliest dated records. Press $\downarrow$ to page through all the data base records.

3. When the desired survey has been located, press PgDn to move to Table 1 , waste shipped directly to disposal sites.

4. TAB through the entry fields. Type over existing data, delete existing data with the DEL key, or clear the entry with Ctrl-End and enter new data.

Note: Use Shift-F4 to clear a single entry or Shift-F7 to clear the record (the screen). This will not delete changes that have already been saved.

Press F10 to save the data on that screen before moving to the next screen. 
4. Continue pressing PgDn and changing data as needed. Remember to press $\mathbf{F 1 0}$ after each screen is entered to save the data.

\section{Delete a Survey}

1. To delete an existing survey, begin at the survey entry menu (Figure 13). Press F7 to begin search mode. Enter the Date of the survey, the Facility ID (generator ID), and Response No. at the top of the first survey entry screen. These three data entry fields must be filled.

2. Press $\mathbf{F} \mathbf{8}$ to begin the search for the specified Date and Facility ID.

- If the Facility ID is unknown, use F9 to scan through the current generator IDs. Move the cursor to the Facility ID field, and press F9. Press TAB or ENTER to scroll through the list of current generator IDs. To select a generator ID, press Shift-F10.

- If the date is unknown, select a generator ID and then press $\downarrow$ to page through all the records for that generator ID. The Date field updates as each new set of records is reached.

Note: It may take some time to move through lengthy records. To check if the tracking system is actually paging through records as you press 1 , note the counter at the bottom right of the screen. If the counter is moving, the system is paging through records.

- If the Date, Facility ID, and Response No. are not known, press F8 instead of pressing F7 in Step 1. This resets the records to the first alphabetically listed generator and the earliest dated records. Press $\downarrow$ to page through all the data base records.

3. When the desired survey has been located, press PgDn to move down through the tables. Press F5 to delete tables. The screen prompts you to press F10 to confirm the deletions.

Note: Every table must be deleted to remove an entire survey. 


\section{Print a Survey}

1. To print an existing survey entry screen, enter the Date of the survey, the Facility ID (generator ID), and Response No. (if known) at the top of the first survey entry sc: $n$.

2. Press $\mathbf{F 8}$ to begin the search for the specified Date and Facility ID.

- If the Facility ID is unknown, use F9 to scan through the current generator IDs. Move the cursor to the Facility ID field, and press F9. Press TAB or ENTER to scroll through the list of current generator IDs. To select a generator ID, press Shift-F10.

- If the date is unknown, select a generator ID and then press $\downarrow$ to page through all the records for that generator ID. The Date field updates as each new set of records is reached.

Note: It may take some time to move through lengthy records. To check it the tracking system is actually paging through records as you press 1 , note the counter at the bottom right of the screen. If the counter is moving, the system is paging through records.

- If the Date, Facility ID, and Response No. are not known, press F8 instead of pressing F7 in Step 1. This resets the records to the first alphabetically listed generator and the earliest dated records. Press $\downarrow$ to page through all the data base records.

3. When the desired survey has been located, press Shift-F2 to print the survey report. 


\section{Table 1. Waste Shipped Directly to Disposal Site}

This table corresponds with Table 1 of the survey, "Waste Shipped Directly to Low-Level Waste Disposal Site(s)."

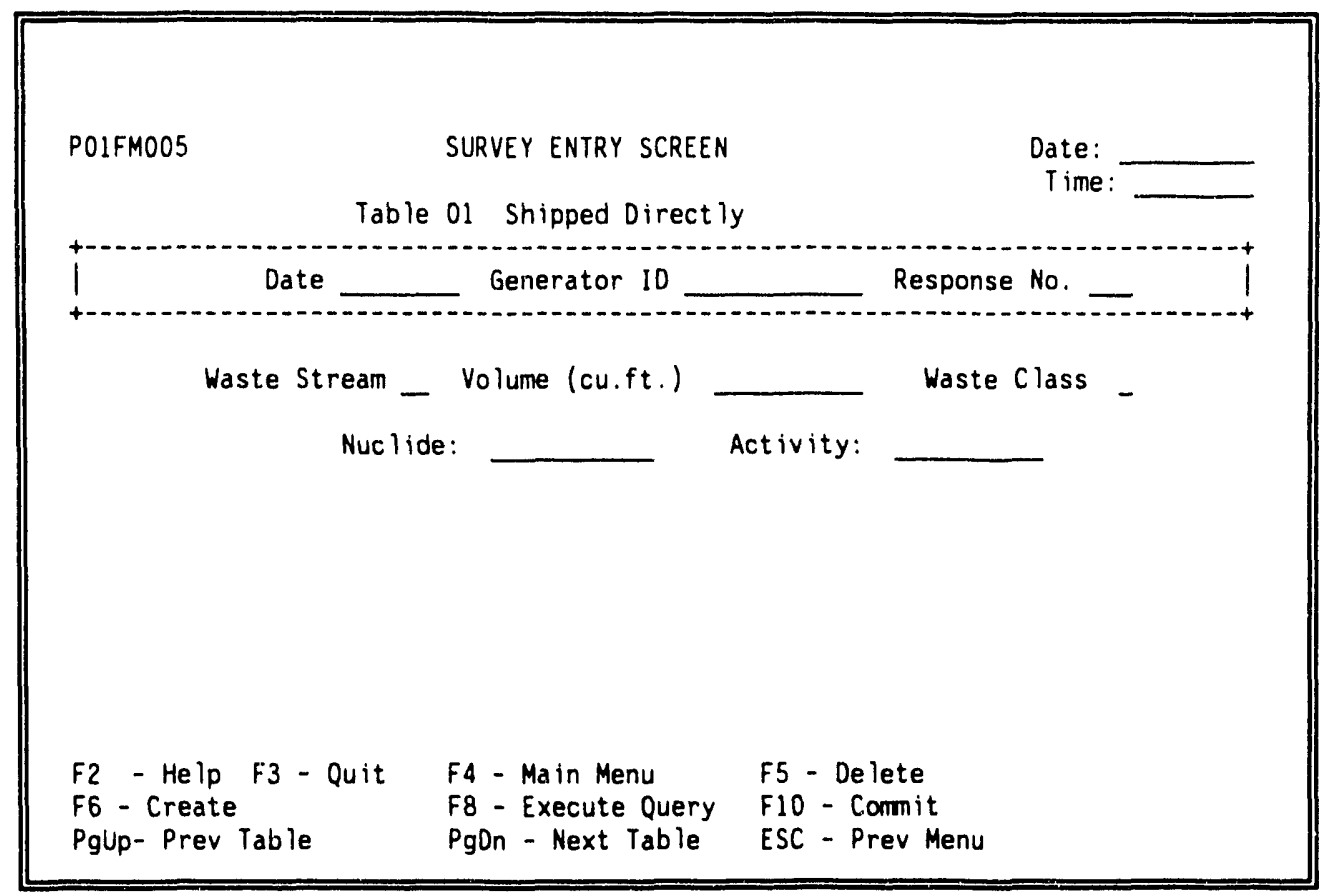

Figure 14. Entry screen for waste shipped directly to disposal site

1. To enter new survey data, press $\mathbf{F} \mathbf{6}$ to begin data entry mode. TAB to the first field and type the two-digit waste stream code. This code must be entered. If the code is unknown, press F9 to scan through the waste stream data lookup table (Figure 6). Press TAB or ENTER to scroll through the waste stream codes. Press Shift-F10 to select a code.

Note: It is more efficient to go through the survey before data entry begins and note the waste stream code for each waste stream on the survey.

2. TAB to the Volume field. Enter volume of waste in cubic feet. 
3. TAB to the Waste Class field. Enter waste class (A, B, or C). This code must be entered.

4. TAB to the Nuclide field. Press F9 to access the lookup table for nuclides. Press TAB or ENTER to scroll through the list of nuclides. Press Shift-F10 to select a nuclide.

Note: Nuclides listed in this field must match the nuclides listed in the nuclide table, or the tracking system will not move to the next screen. If a previously unused nuclide appears on a survey, add that nuclide to the nuclide lookup table before entering the survey data (see Maintaining Lookup Tables).

5. TAB to the Activity field. Enter the waste activity in millicuries. If the activity is given in another measurement, such as curies, convert it to millicuries before entering the amount on the survey entry screen.

6. Press $\mathbf{F} 10$ to save the changes to this data entry screen. The tracking program compares the Waste Stream, Waste Class, and Nuclide entries to the data lookup tables. The screen prompts you to verify the changes by pressing F10 again.

Note: The data must match the lookup tables before the tracking system will proceed to the next table. If necessary, press F4 to exit the data entry screen. Type 4 (Lookup Table Maintenance) and press ENTER at the main menu to update the lookup tables.

7. After the data is saved, press PgDn to move to the next data entry screen.

Note: If you do not press F10 and verify the changes to be saved, the data will be lost when you page down to the next survey entry screen. 


\section{Table 2. Waste Shipped Through Broker to Disposal Site}

This table corresponds with Table 2 of the survey, "Waste Shipped Through a Broker to LLRW Disposal Site(s)."

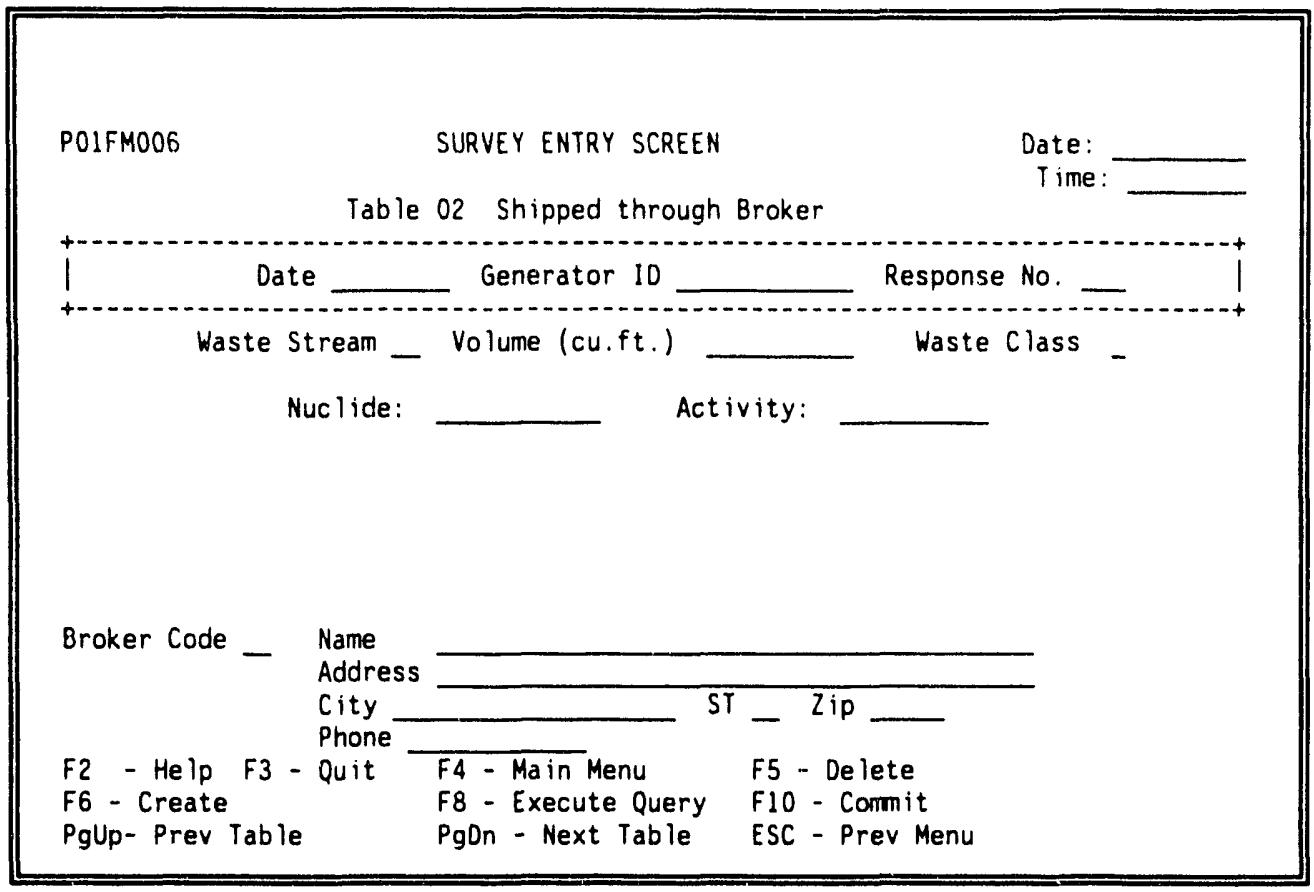

Figure 15. Entry screen for waste shipped through a broker

1. To enter new survey data, press $\mathbf{F} \mathbf{6}$ to begin data entry mode. TAB to the first field and type the two-digit waste stream code. This code must be entered. If the code is unknown, press F9 to scan through the waste stream data lookup table (Figure 6). Press TAB or ENTER to scroll through the waste stream codes. Press Shift-F10 to select a code.

Note: It is more efficient to go through the survey before data entry begins and note the wastc stream code for each waste on the survey.

2. TAB to the Volume field. Enter volume of waste in cubic feet.

3. TAB to the Waste Class field. Enter waste class (A, B, or C). This code must be entered. 
4. TAB to the Nuclide field. Press F9 to access the lookup table for nuclides. Press TAB or ENTER to scroll through the list of nuclides. Press Shift-F10 to select a nuclide.

Note: Nuclides listed in this field must match the nuclides listed in the nuclide table, or the tracking system will not move to the next screen. If a previously unused nuclide appears on a survey, add that nuclide to the nuclide lookup table before entering the survey data (see Maintaining Lookup Tables).

5. Press $!$ to move to the next field to enter the next nuclide. If the cursor has been positioned without entering data, press Shift-F4 to clear entry.

6. TAB to the Activity field. Enter the waste activity in millicuries. If the activity is given in another measurement, such as curies, convert it to millicuries before entering the amount on the survey entry screen.

7. TAB the Broker Code field. This code must be entered. Press F9 to access the lookup table for broker/processors. Press TAB or ENTER to scroll through the list. Press Shift-F10 to select a broker. The tracking system automatically fills out the name and address for the broker.

Note: Brokers listed in this field must match the broker/processor lookup table, or the tracking system will not move to the next screen. If a previously unrecorded broker appears on a survey, add that broker to the broker/processor lookup table before entering the survey data (see Maintaining Lookup Tables).

8. Press $\mathbf{F 1 0}$ to save the changes to this data entry screen. The tracking program compares the Waste Stream, Waste Class, Nuclide, and Broker entries to the data lookup tables. The screen prompts you to press F10 again to verify the save.

Note: The data must match the lookup tables before the tracking system will proceed to the next table. If necessary, press F4 to exit the data entry screen. Type 4 (Lookup Table Maintenance) and press ENTER at the main menu to update the lookup tables.

9. After the data is saved, press PgDn to move to the next entry screen.

Note: If you do not press $\mathbf{F 1 0}$ and verify the changes to be saved, the data will be lost when you page down to the next survey entry screen. 


\section{Table 3. Mixed Waste Generated}

This table corresponds with Table 3 of the survey, "Mixed Waste Generated."

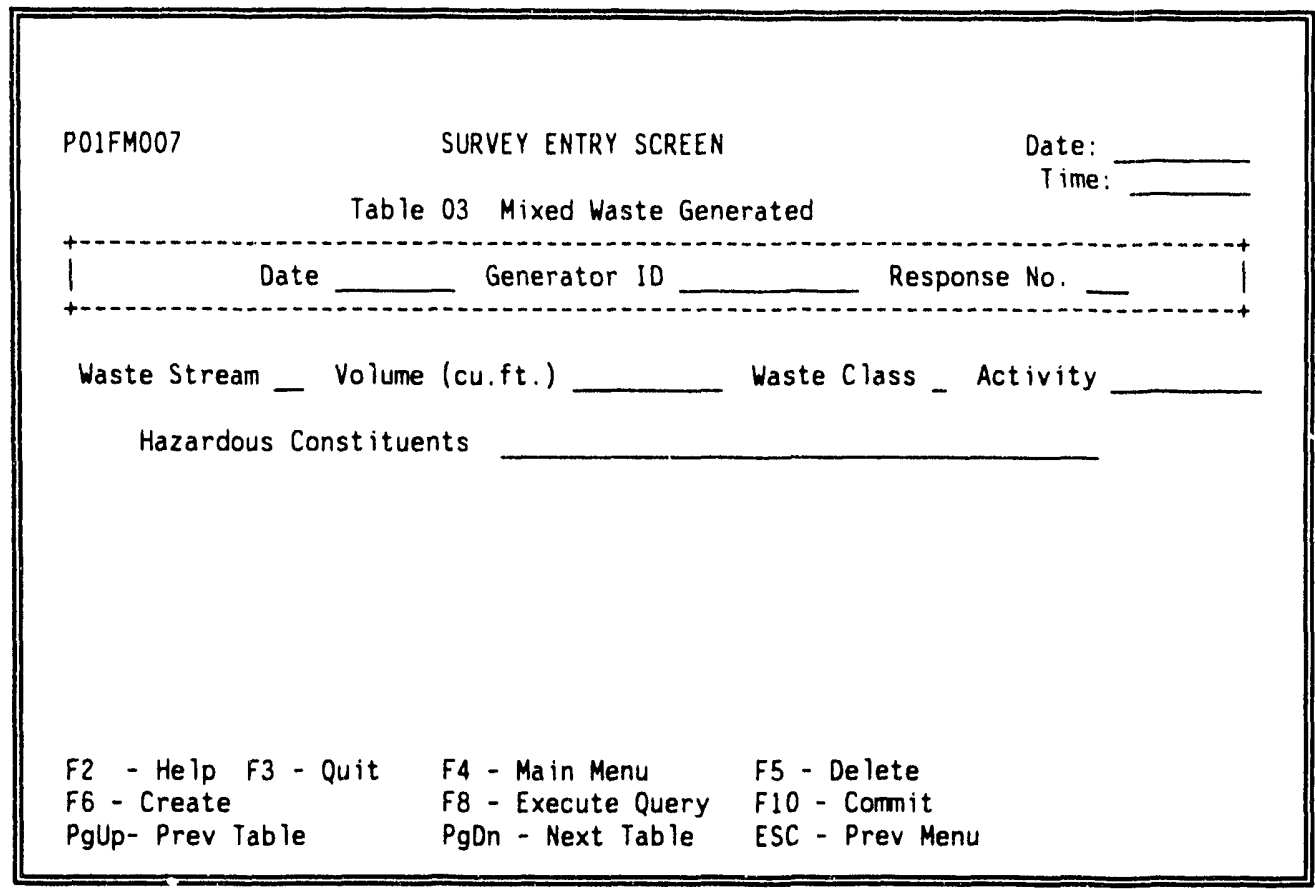

Figure 16. Entry screen for mixed waste generated

1. To enter new survey data, press $\mathbf{F} 6$ to begin data entry mode. TAB to the first field and type the two-digit waste stream code. This code must be entered. If the code is unknown, press F9 to scan through the waste stream data lookup table (Figure 6). Press TAB or ENTER to scroll through the waste stream codes. Press Shift-F10 to select a code.

Note: It is more efficient to go through the survey before data entry begins and note the waste stream code for each waste stream on the survey.

2. TAB to the Volume field. Enter volume of waste in cubic feet. 
3. TAB to the Waste Class field. Enter waste class (A, B, or C). This code must be entered.

4. TAB to the Activity field. Enter the waste activity in millicuries. If the activity is given in another measurement, such as curies, convert it to millicuries before entering the amount on the survey entry screen.

5. TAB to the Hazardous Constituents field. Hazardous constituents must be entered. Press F9 to access the lookup table for hazardous constituents. Press TAB or ENTER to scroll through the list. Press Shift-F10 to select a hazardous constituent.

Note: Hazardous constituents listed in this field must match the hazardous constituent lookup table, or the tracking system will not move to the next screen. If a previously unused hazardous constituent appears on a survey, add that constituent to the hazardous constituent lookup table before entering the survey data (see Maintaining Lookup Tables).

6. Press $\mid$ to move to the next field to enter the next hazardous constituent. If the cursor has been positioned without entering data, press Shift-F4 to clear entry.

7. Press F10 to save the changes to this data entry screen. The tracking program compares the Waste Stream, Waste Class, and Hazardous Constituent entrie to the data lookup tables. The screen prompts you to press F10 again to verify the save.

Note: The data must match the lookup tables before the tracking system will proceed to the next table. If necessary. press F4 to exit the data entry screen. Type 4 (Lookup Table Maintenance) and press ENTER at the main menu to update the lookup tables.

8. After the data is saved, press PgDn to move to the next data entry screen.

Note: If you do not press F10 and verify the changes to be saved, the data will be lost when you page down to the next survey entry screen. 


\section{Table 4. Waste in Storage at End of Quarter}

This table corresponds with Table 4 of the survey, "Waste in Storage at the End of the Quarter, Awaiting Shipment."

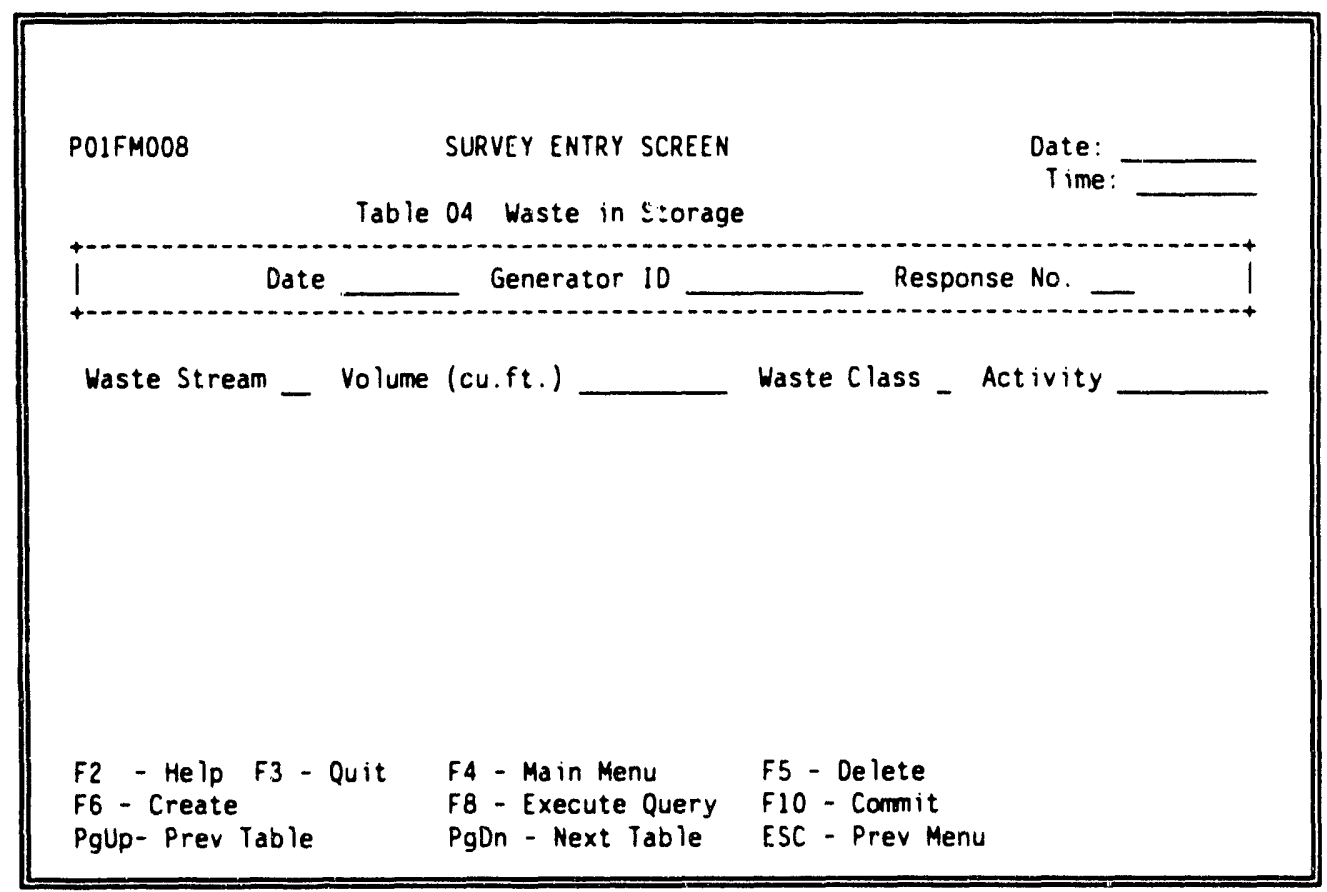

Figure 17. Entry screen for waste in storage at end of quarter

1. To enter new survey data, press $\mathbf{F} 6$ to begin data entry mode. TAB to the first field and type the two-digit waste stream code. This code must be entered. If the code is unknown, press F9 to scan through the waste stream data lookup table (Figure 6). Press TAB or ENTER to scroll through the waste stream codes. Press Shift-F10 to select a code.

Note: It is more efficient to go through the survey before data entry begins and note the waste stream code for each waste stream on the survey.

2. TAB to the Volume field. Enter volume of waste in cubic feet. 
3. TAB to the Waste Class field. Enter waste class (A, B, or C). This code must be entered.

4. TAB to the Activity field. Enter the waste activity in millicuries. If the activity is given in another measurement, such as curies, convert it to millicuries before entering the amount on the survey entry screen.

5. Press F10 to save the changes to this data entry screen. The tracking program compares the Waste Stream and Waste Class entries to the data lookup tables. The screen prompts you to press F10 again to verify the save.

Note: The data must match the lookup tables before the tracking system will proceed to the next table. If necessary, press $\mathbf{F} 4$ to exit the data entry screen. Type 4 (Lookup Table Maintenance) and press ENTER at the main menu to update the lookup table'

6. After the data is saved, press PgDn to move to the next data entry screen.

Note: If you do not press $\mathbf{F 1 0}$ and verify the changes to be saved, the data will be lost when you page down to the next survey entry screen. 
Table 5. On-Site Volume Reduction or Processing

This table corresponds with Table 5 of the survey, "On-Site Volume Reduction or Processing."

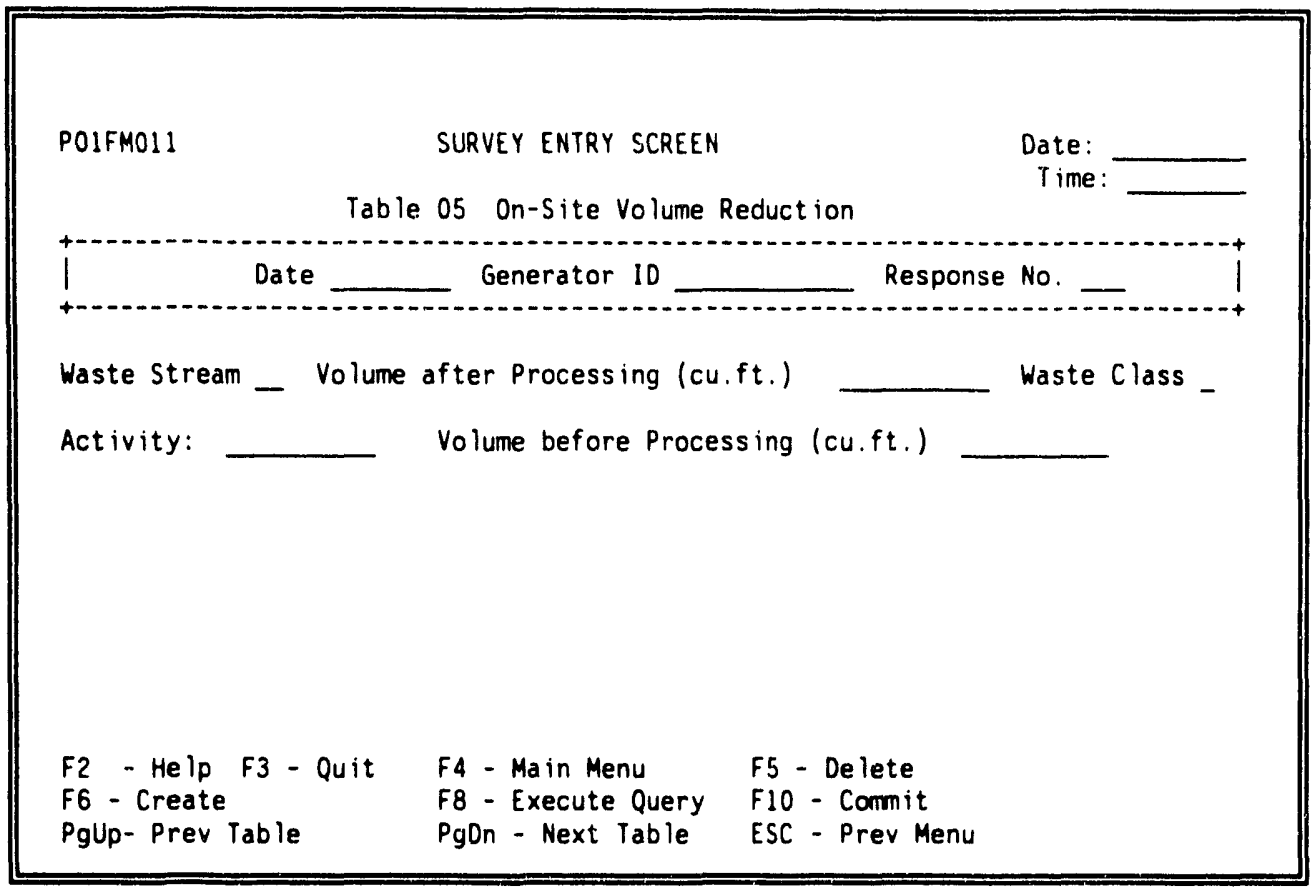

Figure 18. Entry screen for on-site volume reduction or processing

1. To enter new survey data, press $\mathbf{F} 6$ to begin data entry mode. TAB to the first field and type the two-digit waste stream code. This code must be entered. If the code is unknown, press F9 to scan through the waste stream data lookup table (Figure 6). Press TAB or ENTER to scroll through the waste stream codes. Press Shift-F10 to select a code.

Note: It is more efficient to go through the survey before data entry begins and note the waste stream code for each waste stream on the survey.

2. TAB to the Volume after Processing field. Enter volume of waste in cubic feet. 
3. $\quad T A B$ to the Waste Class field. Enter waste class $(A, B$, or $C)$. This code must be entered.

4. TAB to the Activity field. Enter the waste activity in millicuries. If the activity is given in another measurement, such as curies, convert it to millicuries before entering the amount on the survey entry screen.

5. TAB to the Volume before Processing field. Enter the volume of the waste before processing in cubic feet.

6. Press F10 to save the changes to this data entry screen. The tracking program compares the Waste Stream and Waste Class entries to the data lookup tables. The screen prompts you to press F10 again to verify the save.

Note: The data must match the lookup tables before the tracking system will proceed to the next table. If necessary, press F4 to exit the data entry screen. Type 4 (Lookup Table Maintenance) and press ENTER at the main menu to update the lookup tables.

7. After the data is saved, press PgDn to move to the next data entry screen.

Note: If you do not press F10 and verify the changes to be saved, the data will be lost when you page down to the next survey entry screen. 


\section{Table 6B. Waste Shipped to Disposal Site this Quarter}

This table corresponds with Table 6B of the survey, "Waste Shipped by

Processor to Disposal Site(s) during this Quarter." Note: In surveys dated 1990 or earlier, this survey entry screen corresponds with Table $6 \mathrm{~A}$ of the survey.

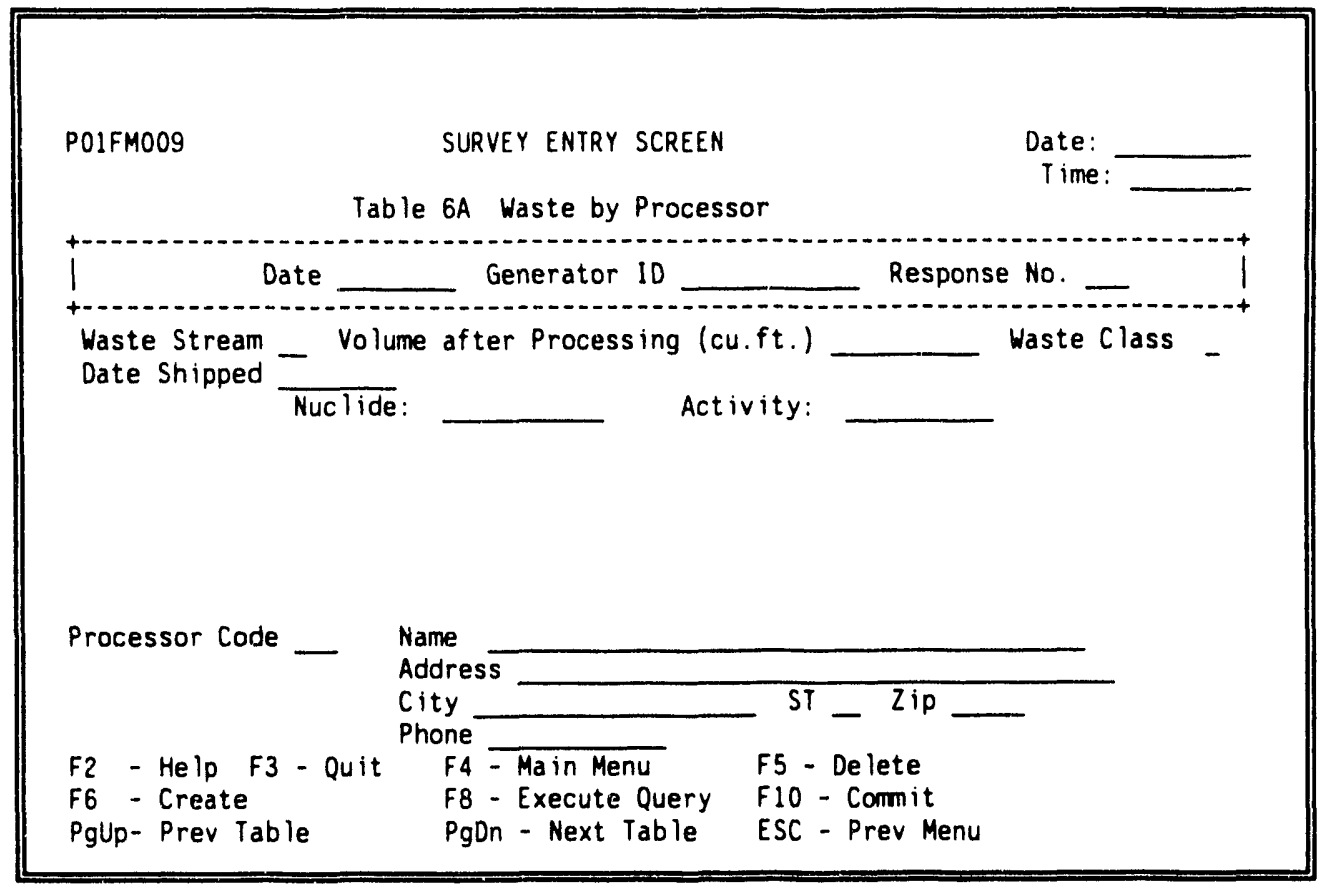

Figure 19. Entry screen for waste shipped for disposal this quarter

1. To enter new survey data, press $\mathbf{F} 6$ to begin data entry mode. TAB to the first field and type the two-digit waste stream code. This code must be entered. If the code is unknown, press F9 to scan through the waste stream data lookup table (Figure 6). Press TAB or ENTER to scroll through the waste stream codes. Press Shift-F10 to select a code.

Note: It is more efficient to go through the survey before data entry begins and note the waste stream code for each waste stream on the survey. 
2. TAB to the Volume after Processing field. Enter volume of waste after processing in cubic feet.

3. TAB to the Waste Class field. Enter waste class (A, B, or $C)$. This code must be entered.

4. TAB to the Nuclide field. Press F9 to access the lookup table for nuclides. Press TAB or ENTER to scroll through the list of nuclides. Press Shift-F10 to select a nuclide.

Note: Nuclides listed in this field must match the nuclides listed in the nuclide table, or the tracking system will not move to the next screen. If a previously unused nuclide appears on a survey, add that nuclide to the nuclide lookup table before entering the survey data (see Maintaining Lookup Tables).

5. TAB to the Activity field. Enter the waste activity in millicuries. If the activity is given in another measurement, such as curies, convert it to millicuries before entering the amount on the survey entry screen.

6. TAB to the Processor Code field. This code must be entered. Press F9 to access the lookup table for broker/processors. Press TAB or ENTER to scroll through the list. Press Shift-F10 to select a processor. The tracking system automatically fills out the name and address for the selected processor.

Note: Processors listed in this field must match the broker/processor lookup table, or the tracking system will not move to the next screen. If a previously unrecorded processor appears on a survey, add that processor to the broker/processor lookup table before entering the survey data (see Maintaining Lookup Tables).

7. TAB to the Date Shipped field. Enter the date the waste was shipped off site for processing.

8. Press F10 to save the changes to this data entry screen. The tracking program compares the Waste Stream, Waste Class, Nuclide, and Processor entries to the data lookup tables. The screen prompts you to press $\mathbf{F 1 0}$ again to verify the save. 
Note: The data must match the lookup tables before the tracking system will proceed to the next table. If necessary, press F4 to exit the data entry screen. Type 4 (Lookup Table Maintenance) and press ENTER at the main menu to update the lookup tables.

9. After the data is saved, press PgDn to move to the next data entry screen.

Note: If you do not press F10 and verify the changes to be saved, the data will be lost when you page down to the next survey entry screen. 


\section{Table 6A. Waste Shipped Off-Site for Processing}

This table corresponds with Table 6A of the survey, "Waste Shipped Off-Site (By Your Facility) for Processing." Note: In surveys dated 1990 or earlier, this survey entry screen corresponds with Table $6 \mathrm{~B}$ of the survey.

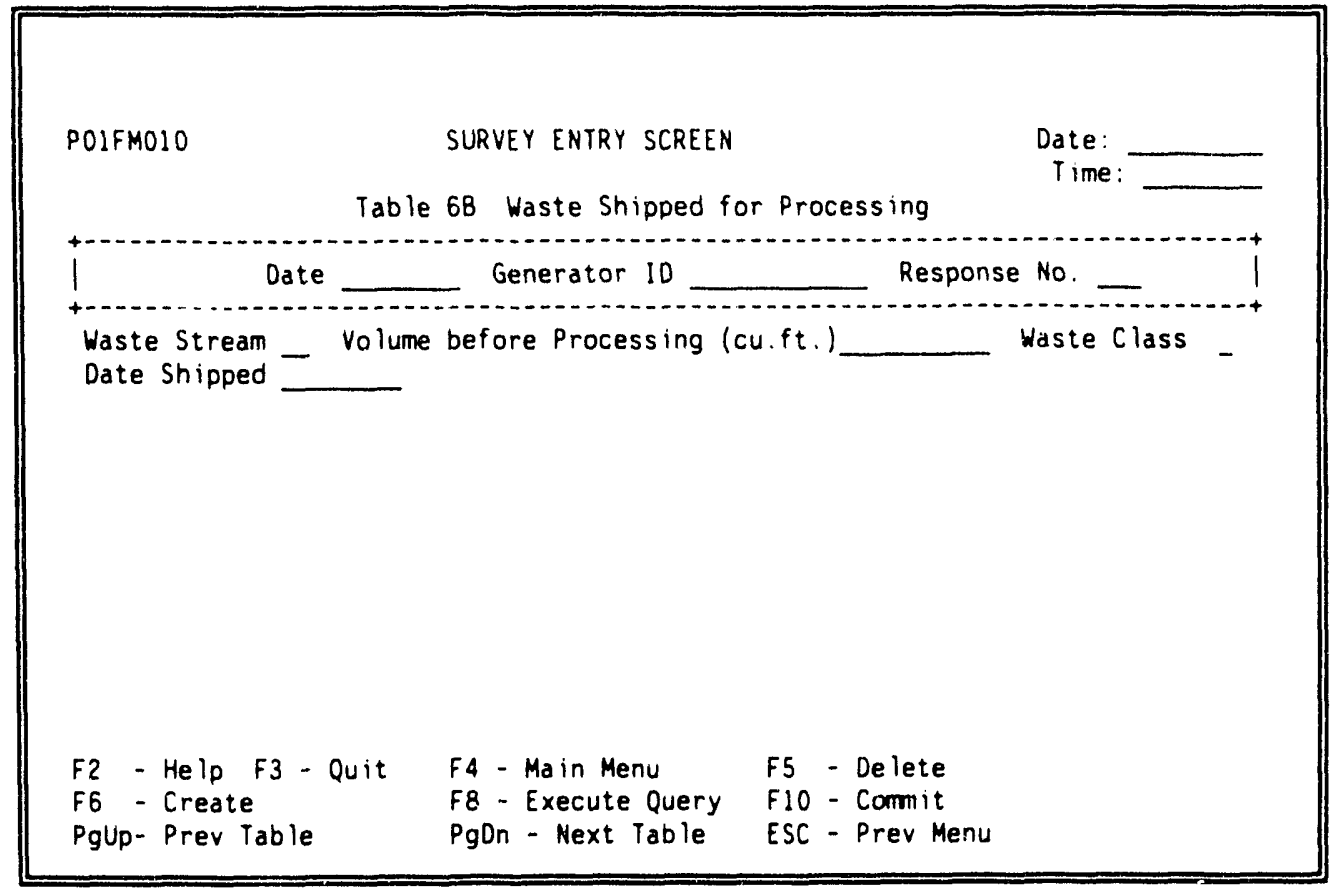

Figure 20. Entry screen for waste shipped off-site for processing

1. To enter new survey data, press $\mathbf{F} 6$ to begin data entry mode. TAB to the first field and type the two-digit waste stream code. This code must be entered. If the code is unknown, press $\mathbf{F 9}$ to scan through the waste stream data lookup table (Figure 6). Press TAB or ENTER to scroll through the waste stream codes. Press Shift-F10 to select a code.

Note: It is more efficient to go through the survey before data entry begins and note the waste stream code for each waste stream on the survey. 
2. TAB to the Volume after Processing field. Enter volume of waste after processing in cubic feet.

3. $\quad$ AAB to the Waste Class field. Enter waste class (A, B, or C). This code must be entered.

4. TAB to the Date Shipped field. Enter the date the waste was shipped off site for processing.

5. Press F10 to save the changes to this data entry screen. The tracking program compares the Waste Stream and Waste Class entries to the data lookup tables. The screen prompts you to press F10 again to verify the save.

Note: The data must match the lookup tables before the tracking system will proceed to the next table. If necessary, press $\mathbf{F} 4$ to exit the data entry screen. Type 4 (Lookup Table Maintenance) and press ENTER at the main menu to update the lookup tables.

6. After the data is saved, press PgDn or ESC to return to the first survey entry screen.

Note: If you do not press F10 and verify the changes to be saved, the data will be lost when you page down to the next survey entry screen. 


\section{Generating Reports}

To generate survey reports, type 3 (Output Tables) at the main menu (Figure 1) and press ENTER. The survey report menu appears. Type the number of the desired report (1-12) and press ENTER.

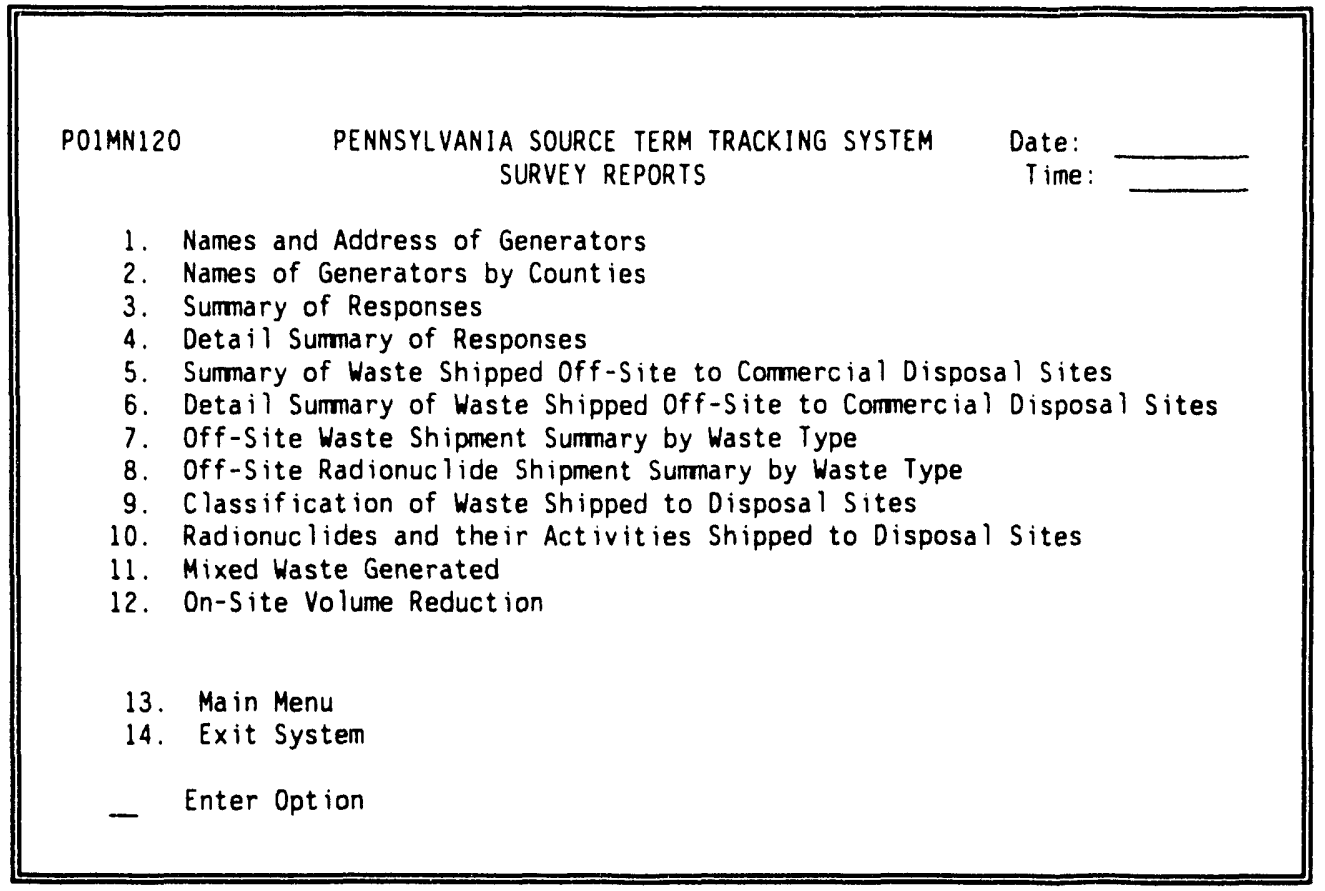

Figure 21. Menu for generating tracking system reports

The menu allows you to select from 12 types of survey reports (output tables). To print a report, type the number of the desired report and press ENTER. The tracking system compiles and prints the report. Appendix A contains examples of the 12 reports.

Note: These reports are generated as hard copy only (printed reports). The tracking system will not save a report to the PC hard drive or to a floppy disk. 
1. Names and Address of Generators

2. Names of Generators by Counties

3. Summary of Responses

4. Detail Summary of Responses

5. Summary of Waste Shipped Off-Site to Commercial Disposal Sites

6. Detail Summary of Waste Shipped Off-Site to Commercial Disposal Sites

7. Off-Site Waste Shipment Summary by Waste Type

8. Off-Site Radionuclide Shipment Summary by Waste Type

9. Classification of Waste Shipped to Disposal Sites

10. Radionuclides and their Activities Shipped to Disposal Sites

11. Mixed Waste Generated

12. On-Site Volume Reduction
Names and addresses of all generators recorded in the tracking system in alphabetical order

Alphabetical list of generators in each county

Breakdown of generators by facility type

Breakdown of generators by facility type and subcategory

Summary of volume and curies shipped off-site to commercial disposal sites by facility type

Summary of volume and curies shipped off-site to commercial disposal sites by facility type and subcategory

Summary of volume and curies shipped off-site to commercial disposal sites by facility type and waste stream

Summary of nuclides shipped off-site to commercial disposal sites by type and waste stream

Summary of waste class volume by facility type and shipment type

Summary of radionuclides

Summary of mixed waste volume and activity by facility type and waste stream

Summary of volume reduction by facility type and waste stream 
Each of the reports allows you to specify a range of dates.

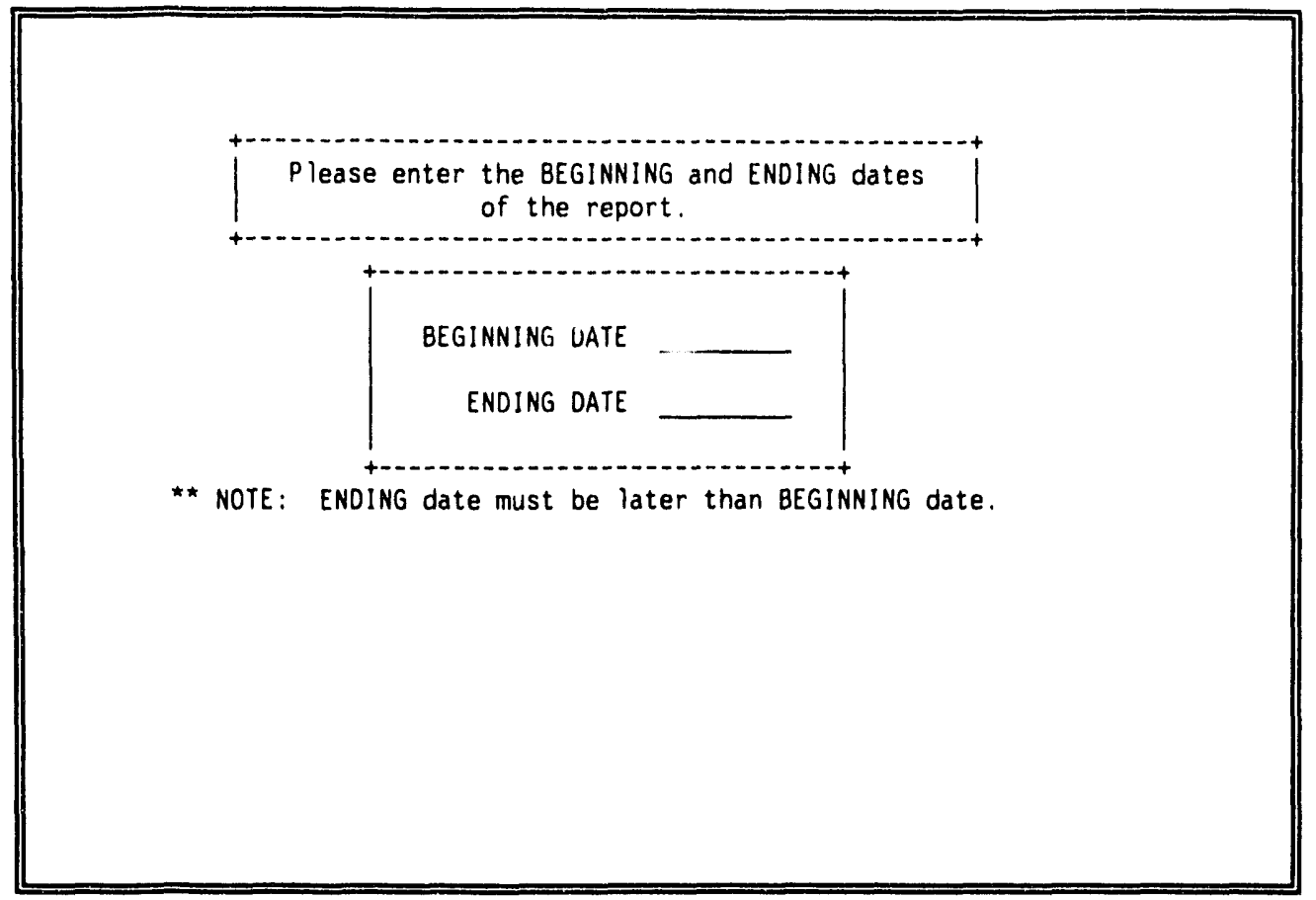

Figure 22. Specify beginning and ending dates for each report.

To print a report, TAB to the entry fields and specify the dates for the report. The format for dates is DD-MM-YY. Press ENTER, and the requested report prints out on the printer. 


\section{Backing Up Tracking System Data}

Use the backup option regularly to copy the data base records to a backup file. To start the procedure, insert a formatted floppy disk in drive A, type 5 (Backup), and press ENTER at the main menu. The example below shows an example of the screen prompts during the procedure. Follow the instructions shown in bold print if you want to accept the default option.

Export: Version 5.1.22.12 on Wed Oct 9 12:10:32 1991

Copyright (c) 1987, Oracle Corporation, California, USA. All rights reserved.

Enter array fetch buffer size(default is 1024)> (Press ENTER)

Export file: EXPDAT.DMP> (Press ENTER)

E(ntire database), U(sers), T(ables): U > (Press ENTER)

Export Grants (Y/N): N > (Press ENTER)

Export the rows $(\mathrm{Y} / \mathrm{N}): \mathrm{Y}>$ (Press ENTER)

Compress extents $(\mathrm{Y} / \mathrm{N}): \mathrm{Y}>$ (Press ENTER)

Exporting Specified Users

User to be exported: MTM > (Press ENTER)

Exporting MTM

.Exporting MTM

.Exporting table p01tb001 100 rows exported

.Exporting table p01tb002 200 rows exported

... an so on through MTM's remaining tables

Exporting Specified Users

User to be exported: MTM > (Type . and press ENTER)

To retrieve the backed up data, consult your Oracle system administrator. 


\section{Appendix A}

\section{Sample Reports}




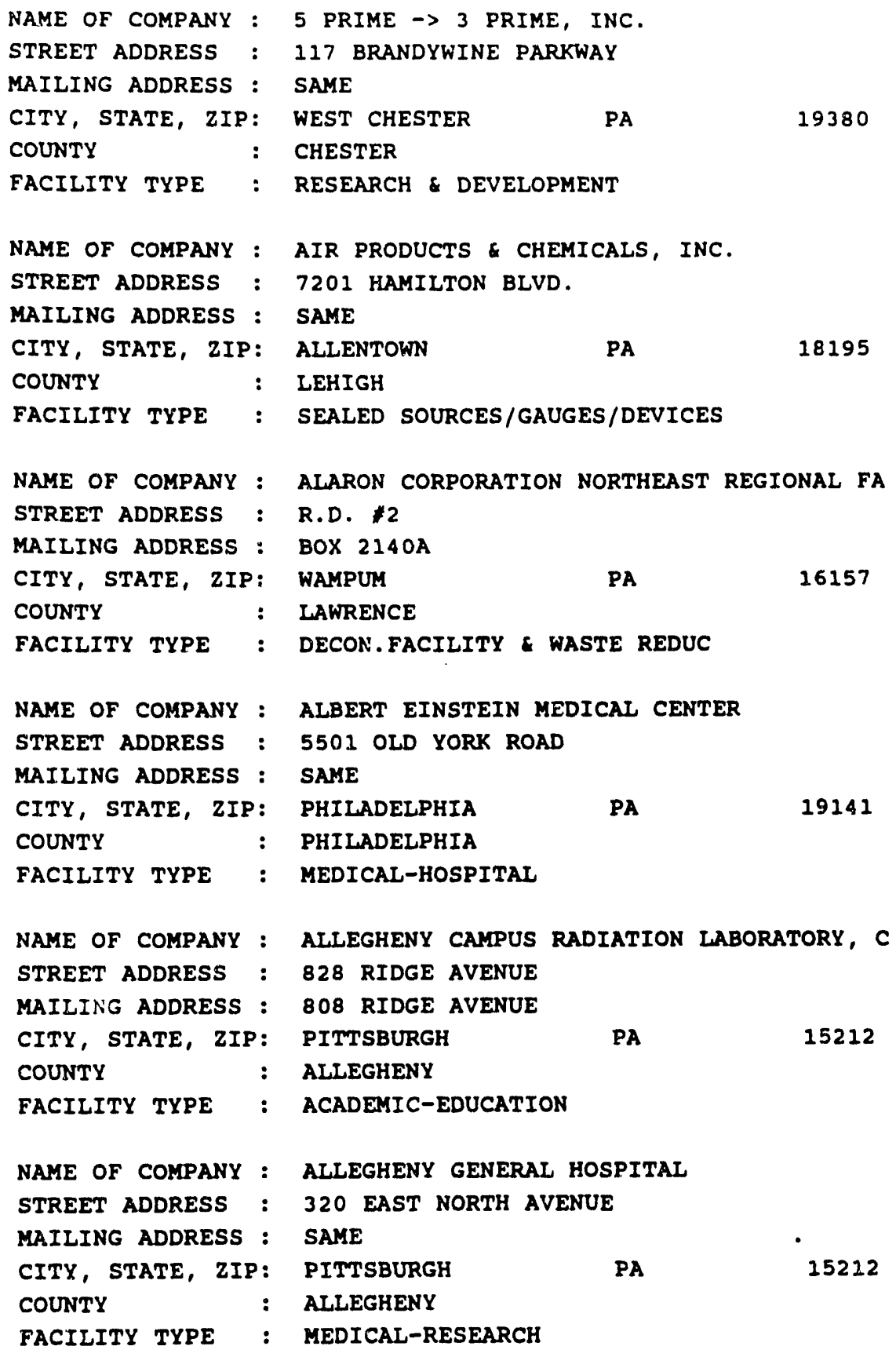


1990 PENNSYLVANIA LLRW REPORT

NAMES OF GENERATORS BY COUNTIES

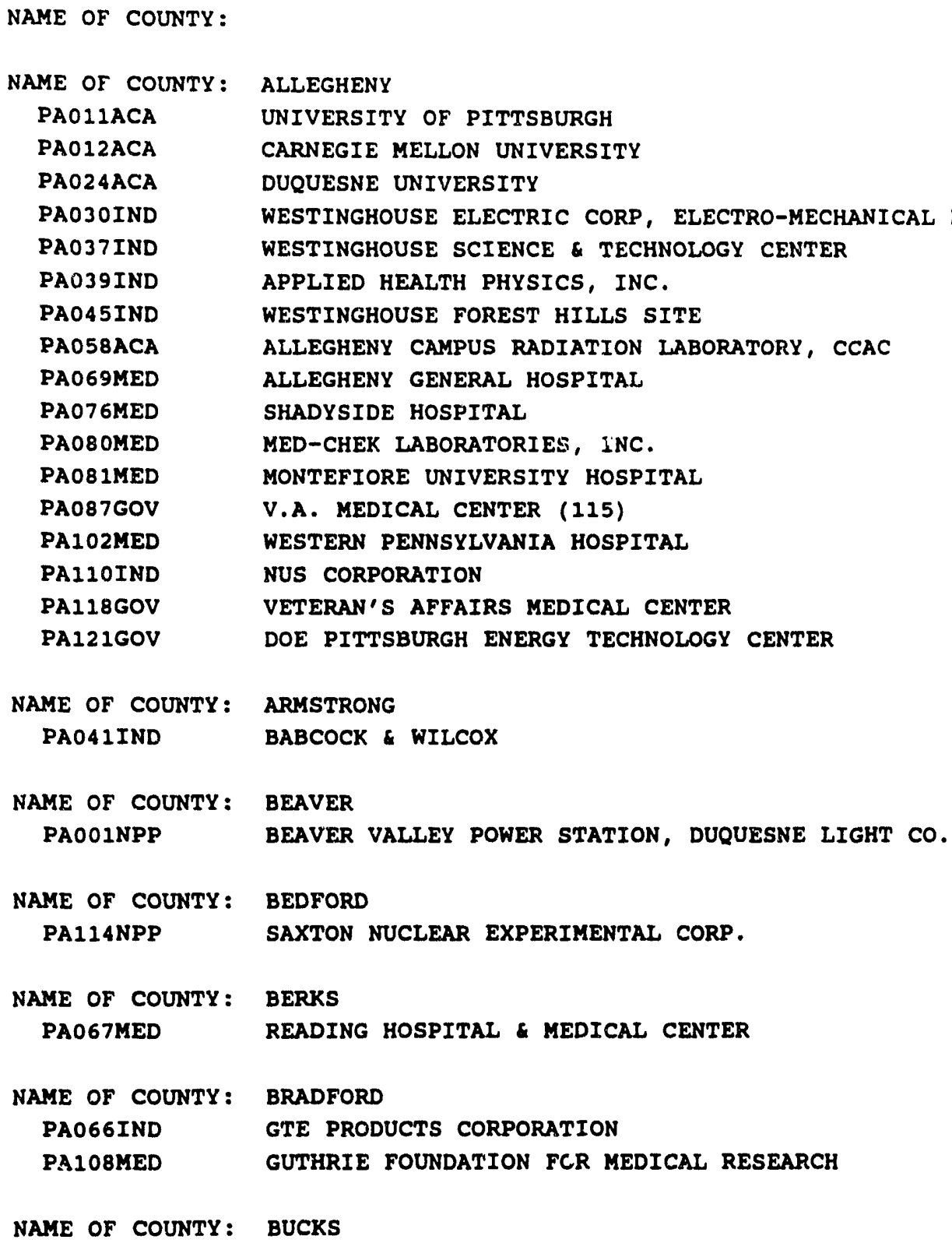


TABLE 3

STATE OF PENNSYLVANIA

SUMMARY OF RESPONSES

FACILITY

NUMBER

1990 GENERATORS

\& OF GENERATORS

NUCLEAR POWER FACILITY

7

MEDICAL (NON-GOVERNMENT)

ACADEMIC

GOVERNMENT

INDUSTRIAL

TOTALS
27

16

30.68

18.18

10.23

32.95

29

- - - -

88

100.00 
TABLE 4

STATE OF PENNSYLVANIA

DETAIL SUMMARY OF RESPONSES

FACILITY
SUB CATEGORY

NUCLEAR POWER FACILITY

NUCLEAR POWER PLAN
MEDICAL (NON-GOVERNMENT)
MEDICAL-HOSPITAL
MEDICAL-IABORATORY
MEDICAL-RESEARCH
MEDICAL COLLEGE/HOSPITAL

ACADEMIC

ACADEMIC-RESEARCH

ACADEMIC-EDUCATION

GOVERNMENT

FEDERAL

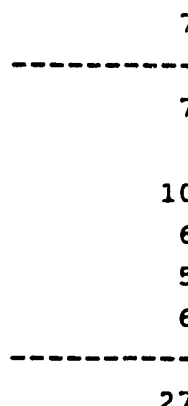

INDUSTRIAL

RESEARCH DEVELOPMENT

MANUFACTURING

DECON.FACILITY WASTE REDUC

NUCLEAR LAUNDRY

ANALYTICAL LABORATORY
1990 GENERATORS

\& OF GENERATORS
27

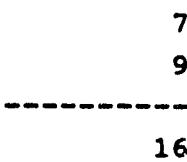

16

9

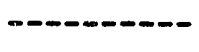

9

7.955

7.955

11.364

6.818

5.682

6.818

30.682

7.955

10.227

18.182

10.227

10.227

16

18.182

7.955

3.409

1.136

2.273

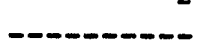

29

32.955

88

100.000

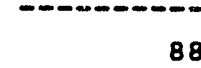

TOTALS 


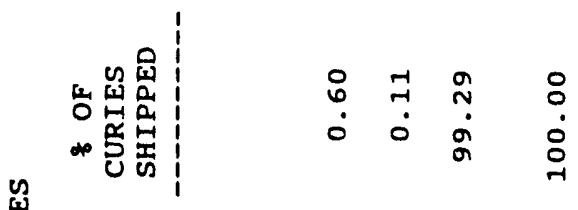

$$
\begin{aligned}
& \text { 息 }
\end{aligned}
$$

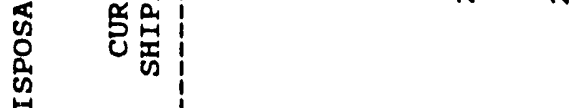

$$
\begin{aligned}
& \text { 点 }
\end{aligned}
$$

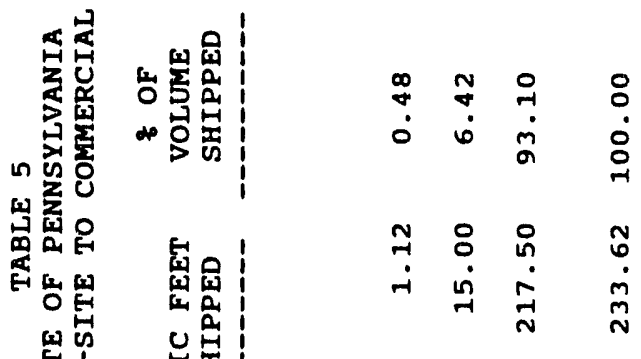

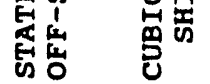

$$
\begin{aligned}
& \text { 鼻 }
\end{aligned}
$$

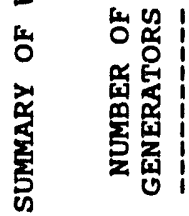

$$
\begin{aligned}
& \text { : }
\end{aligned}
$$




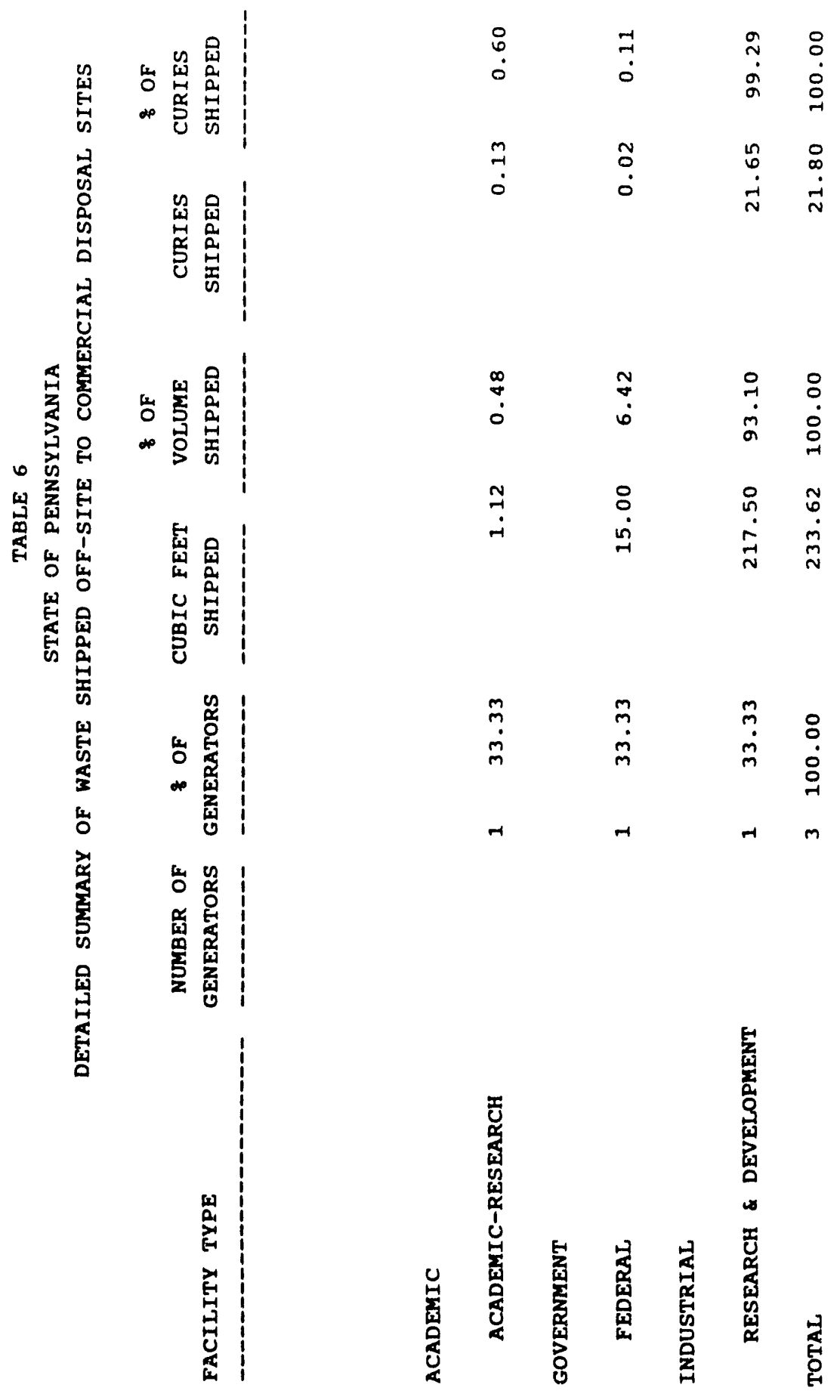




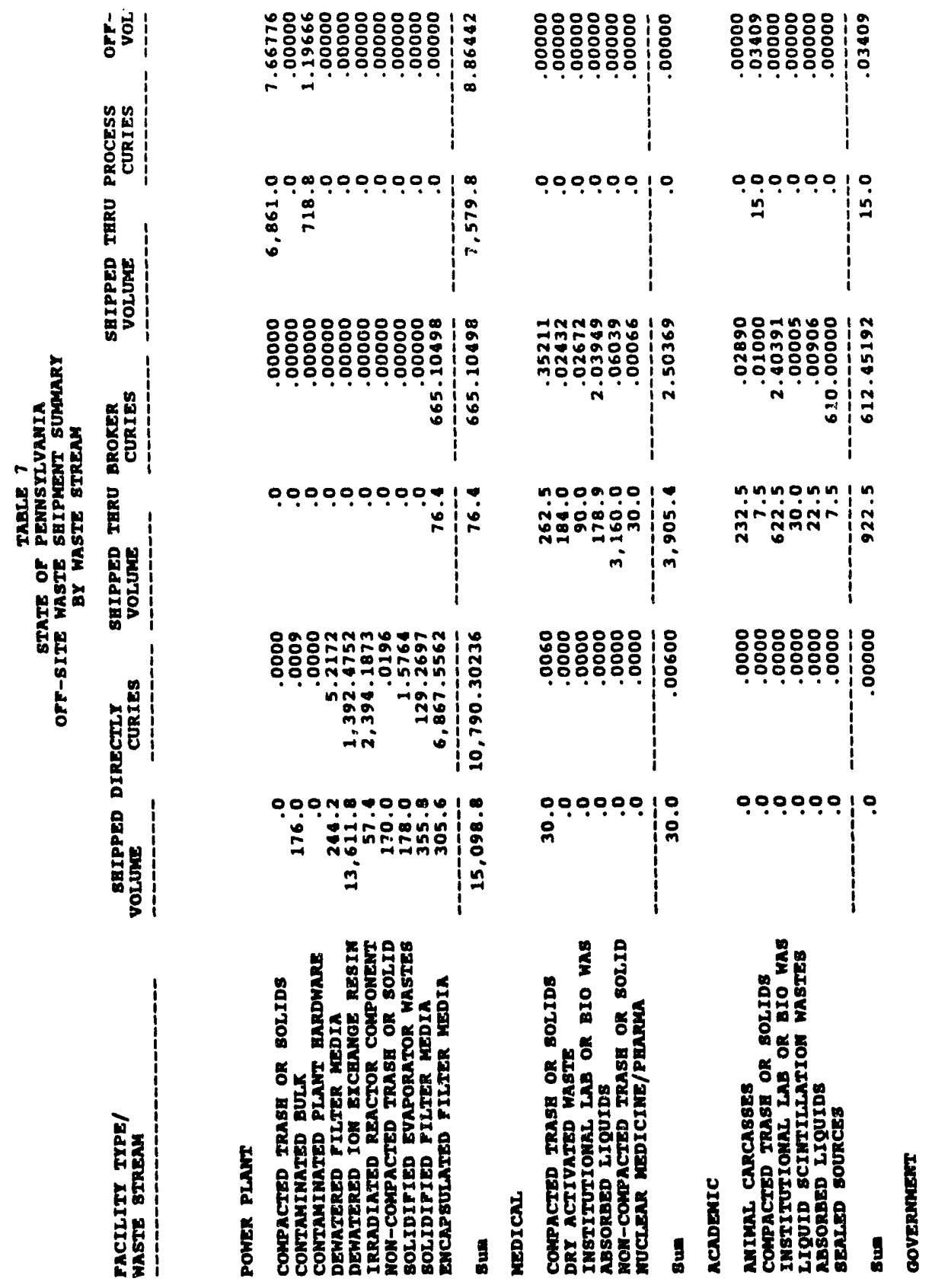




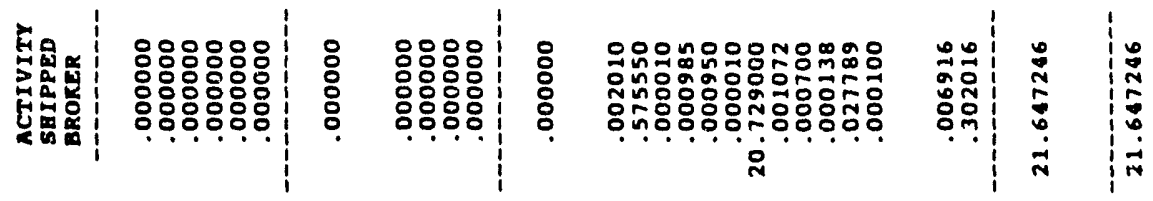

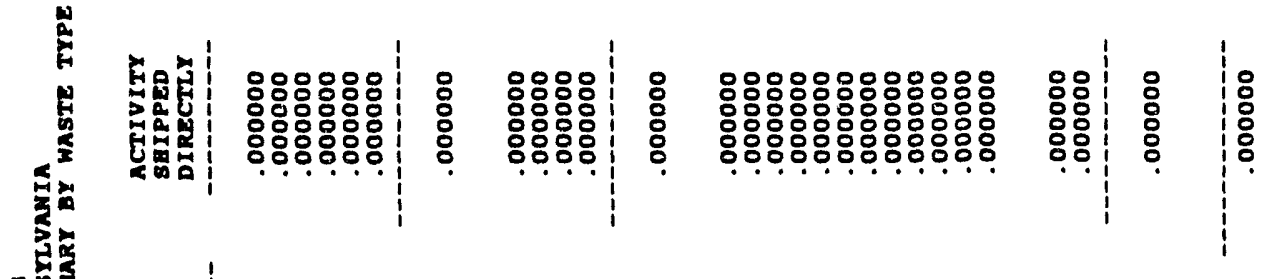

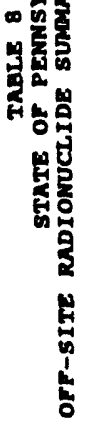
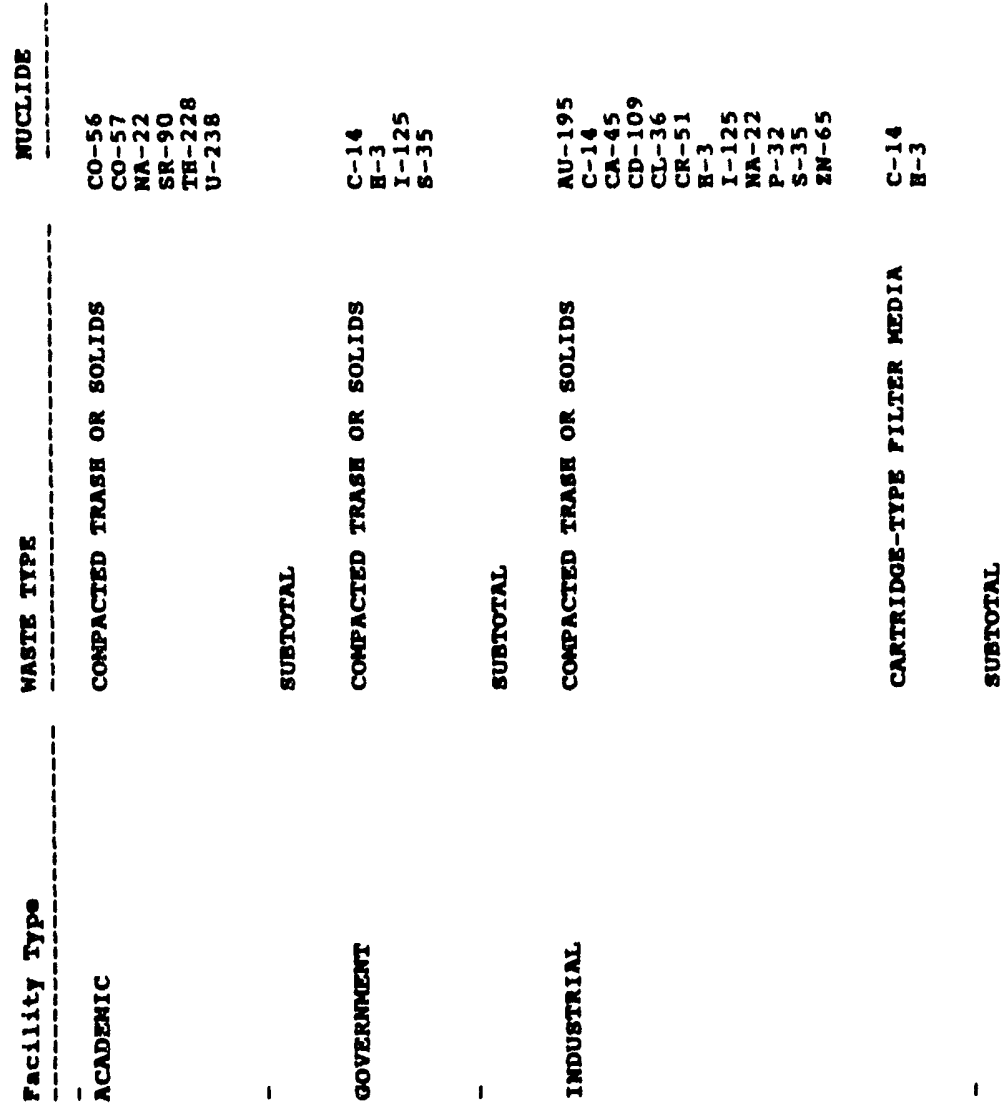

충 


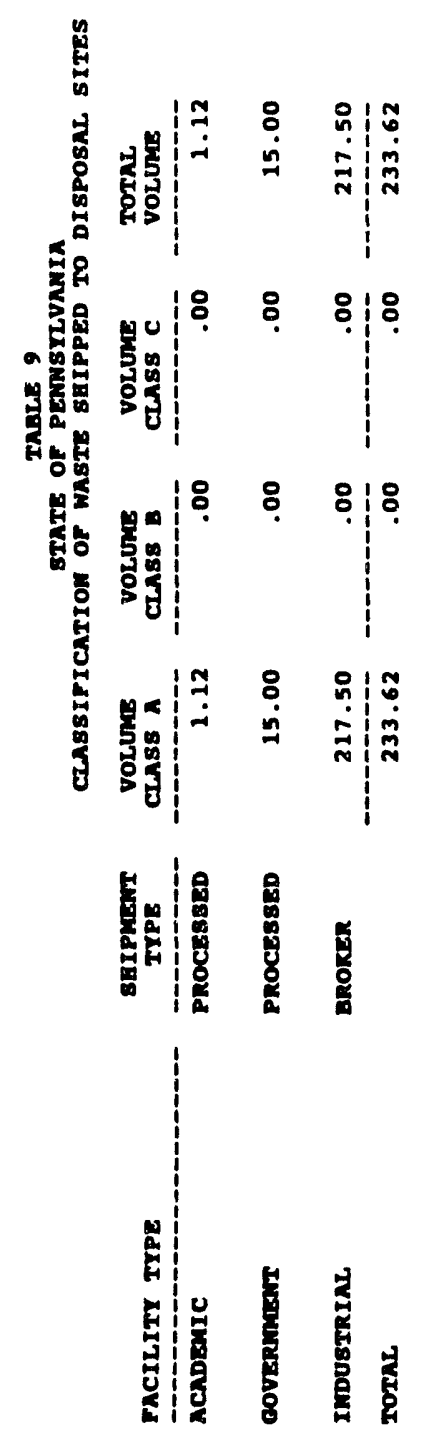



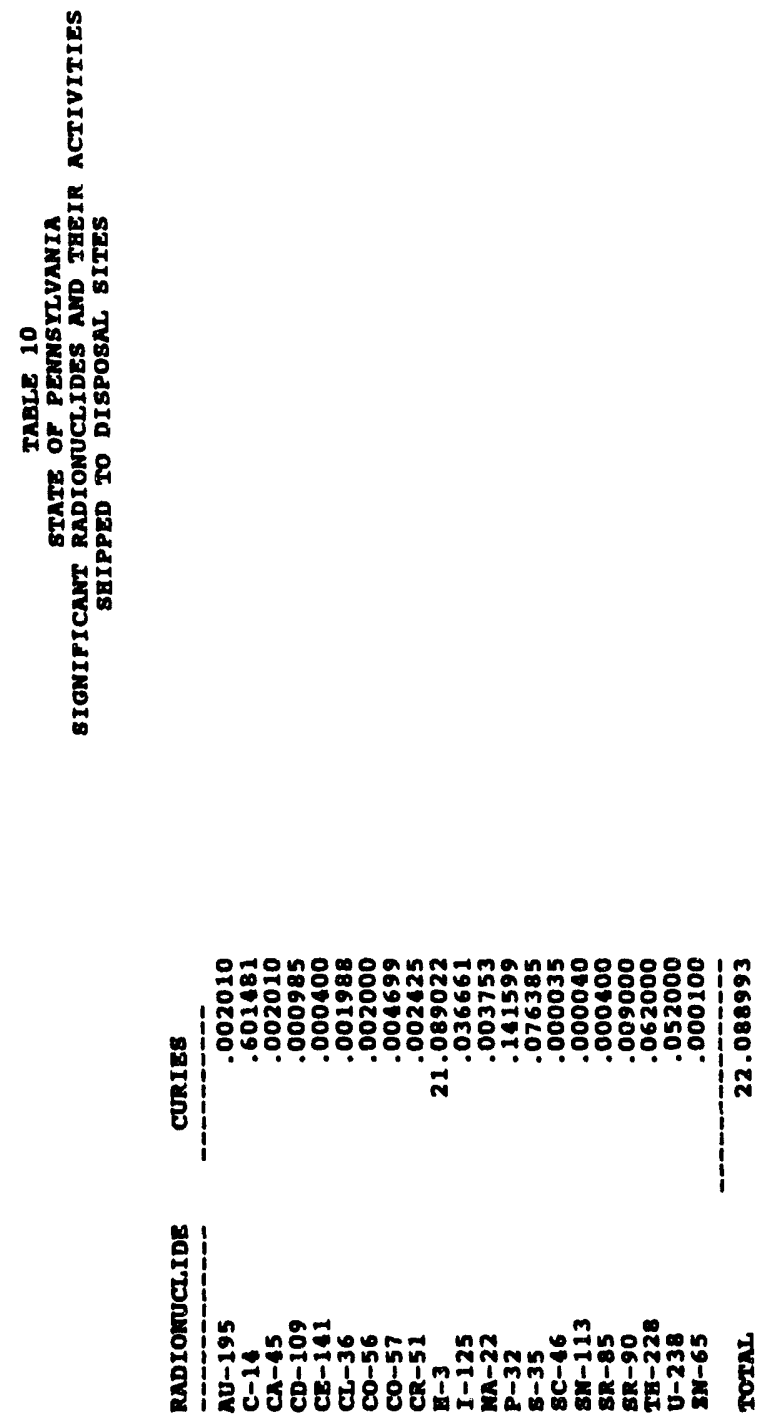
i
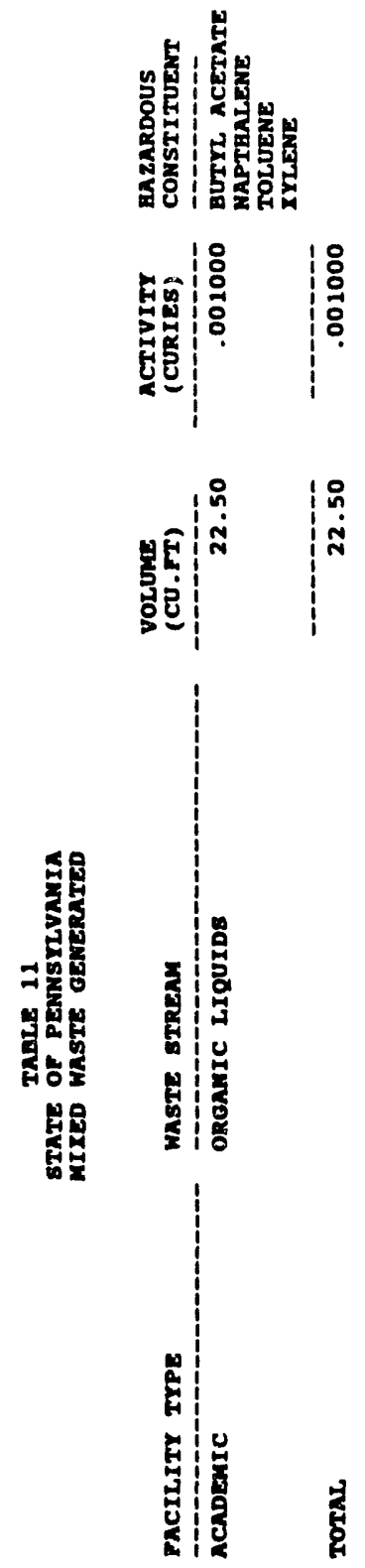


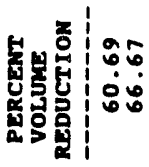
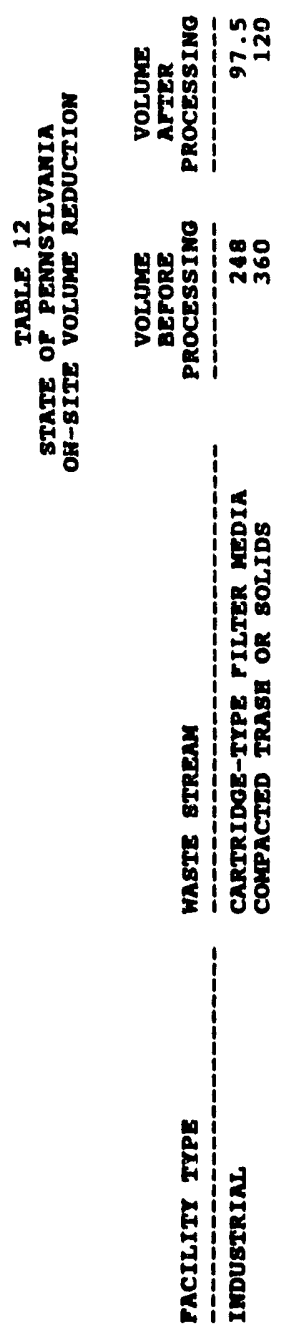

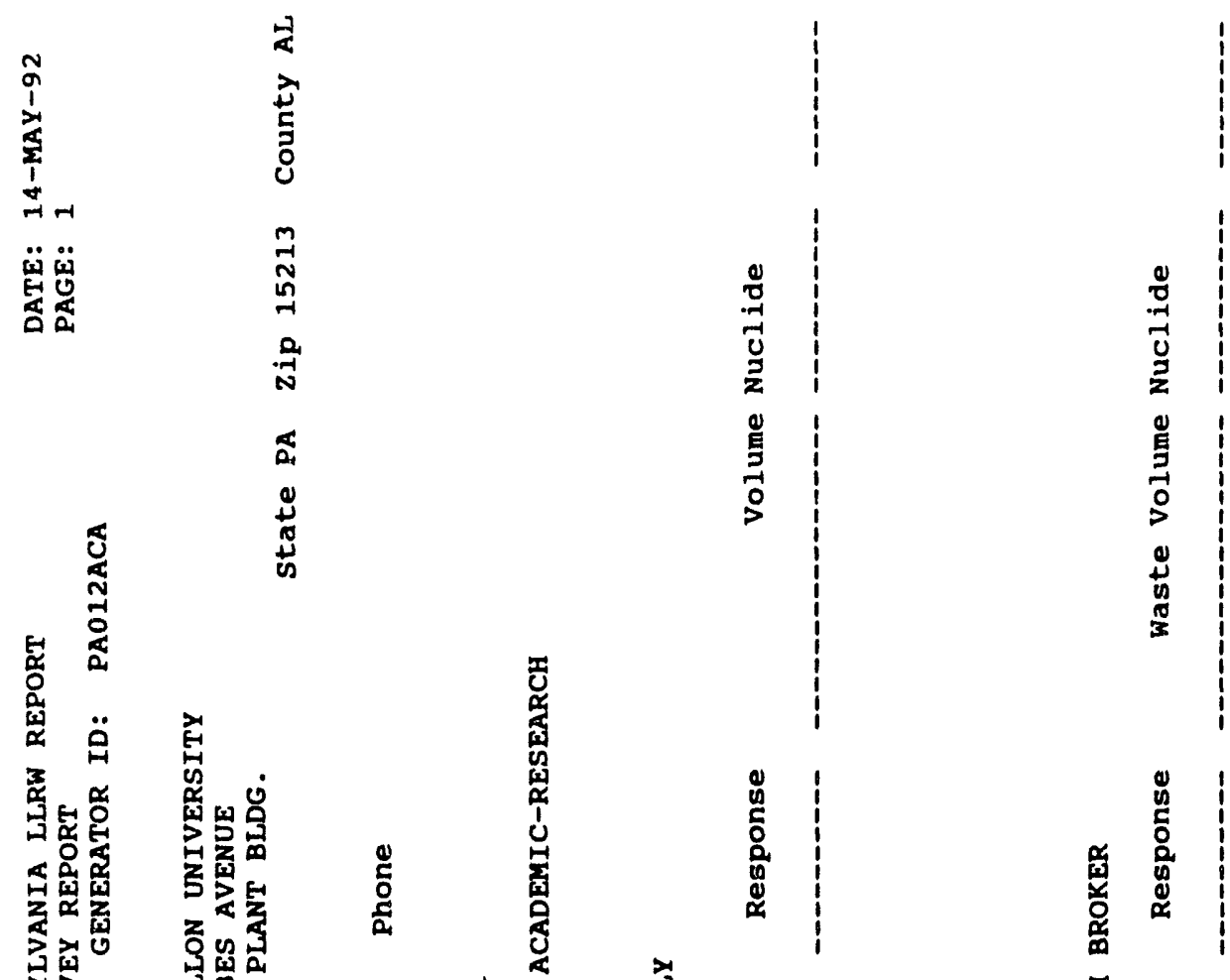

藏若

$\stackrel{m}{\text { m-1 }}$

No

E

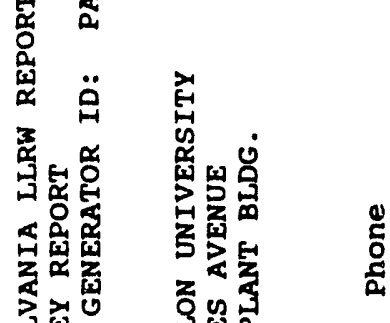

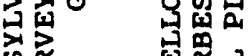

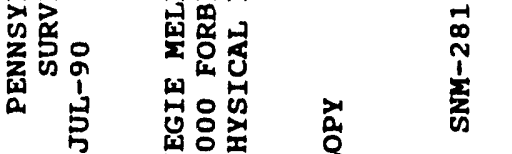

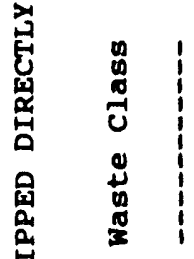

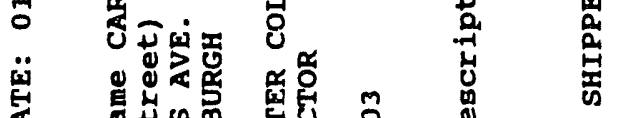

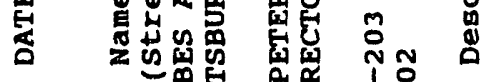

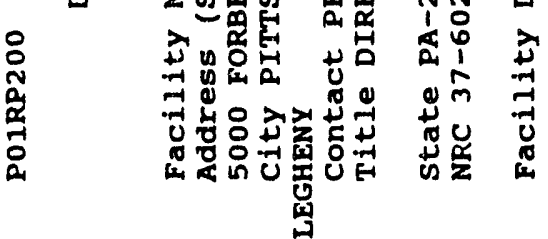

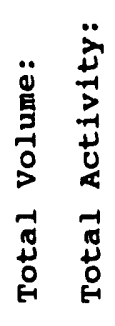

空 

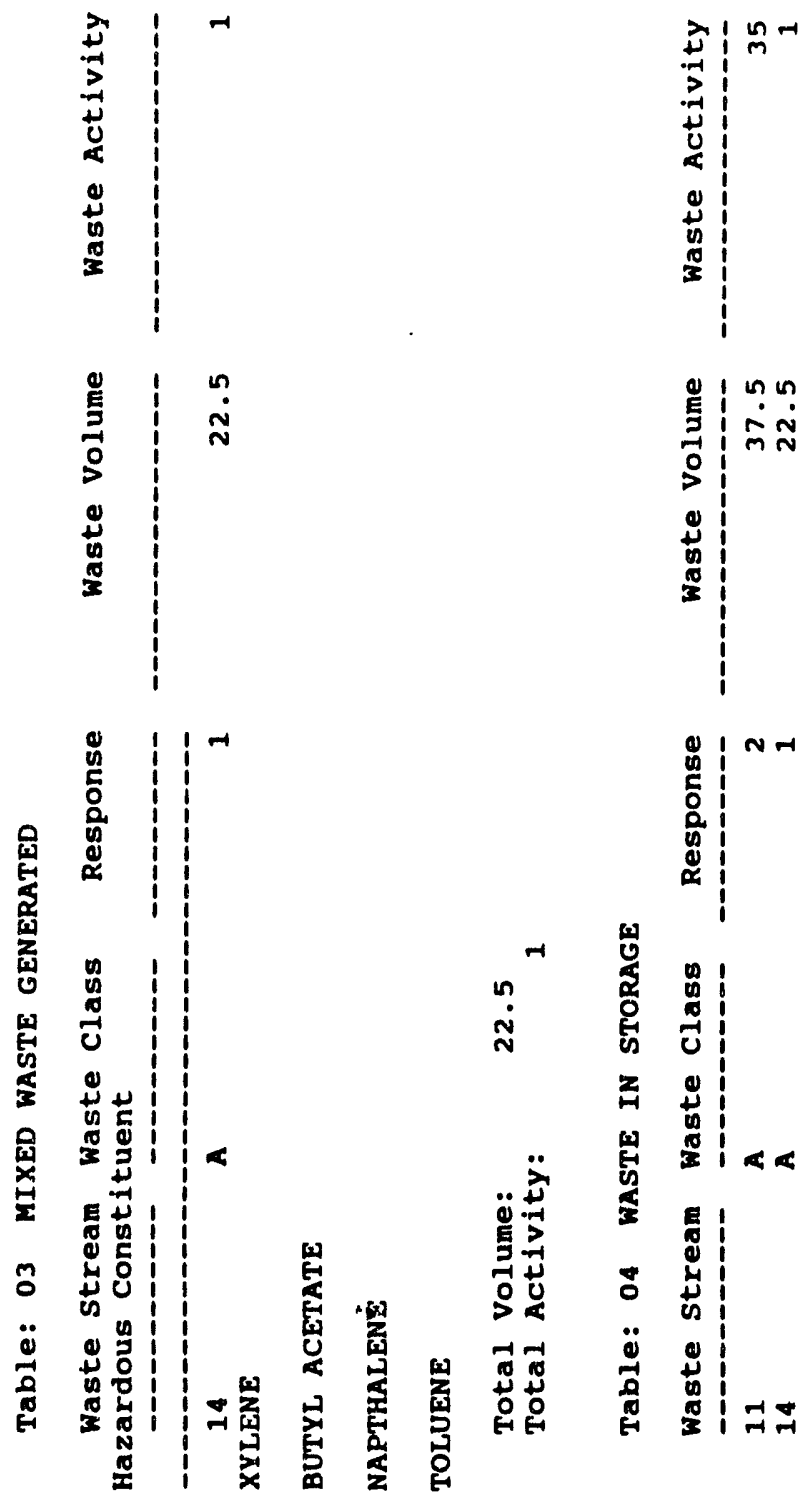


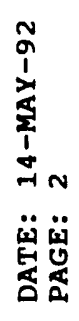

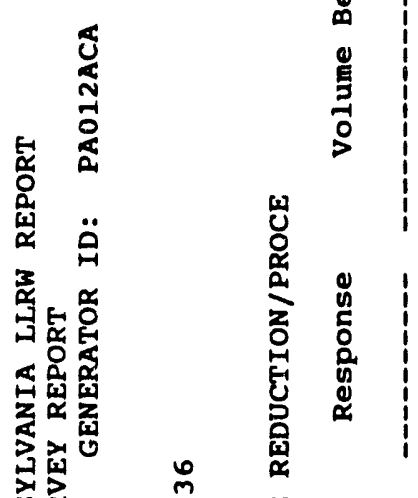

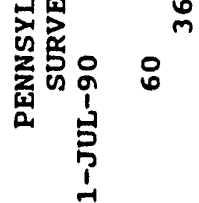

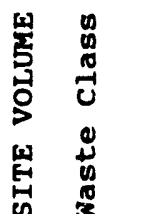

落

○

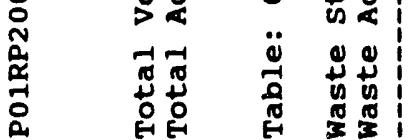

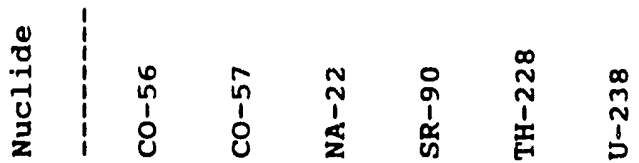

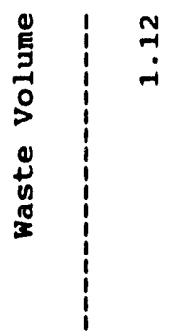

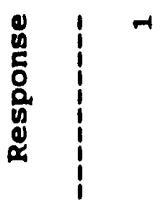

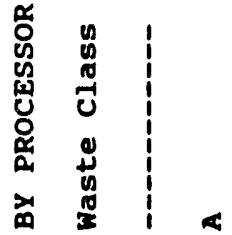

$\ddot{0} \ddot{0}$ 密 苟

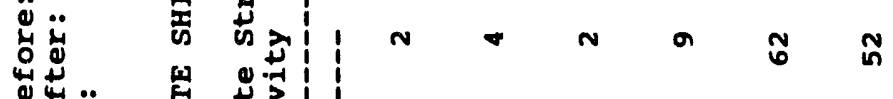

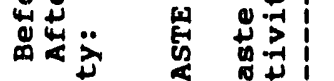

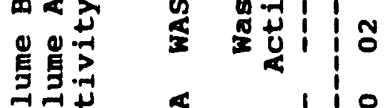

6

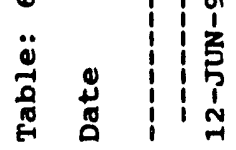


है
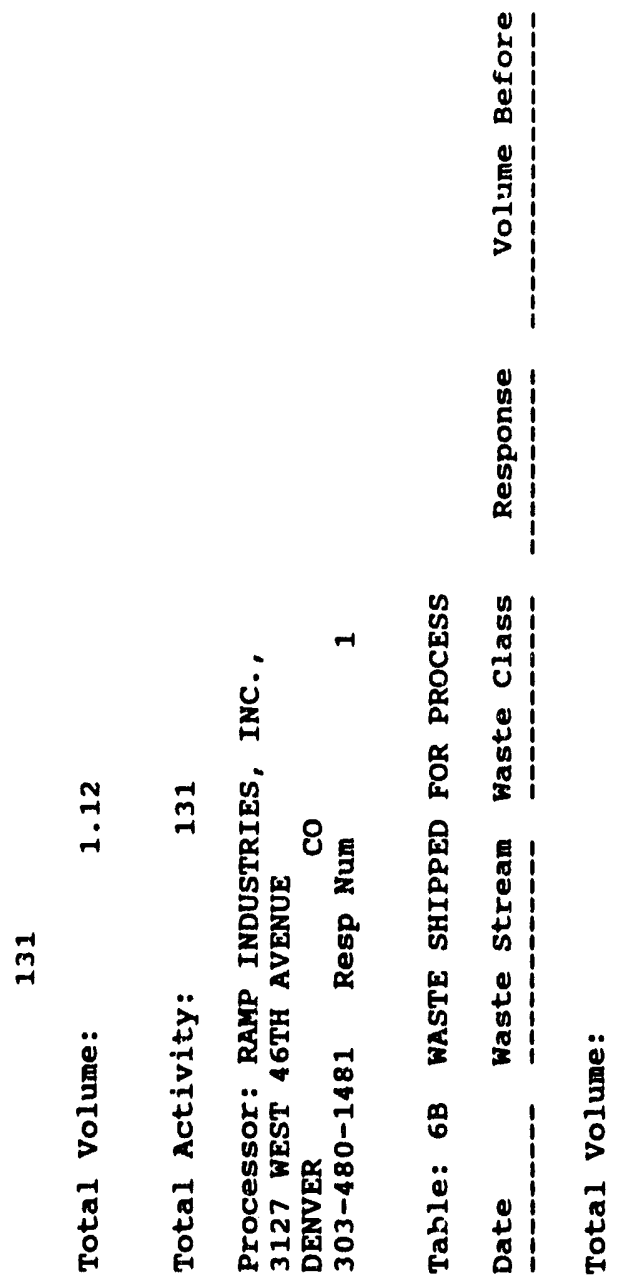

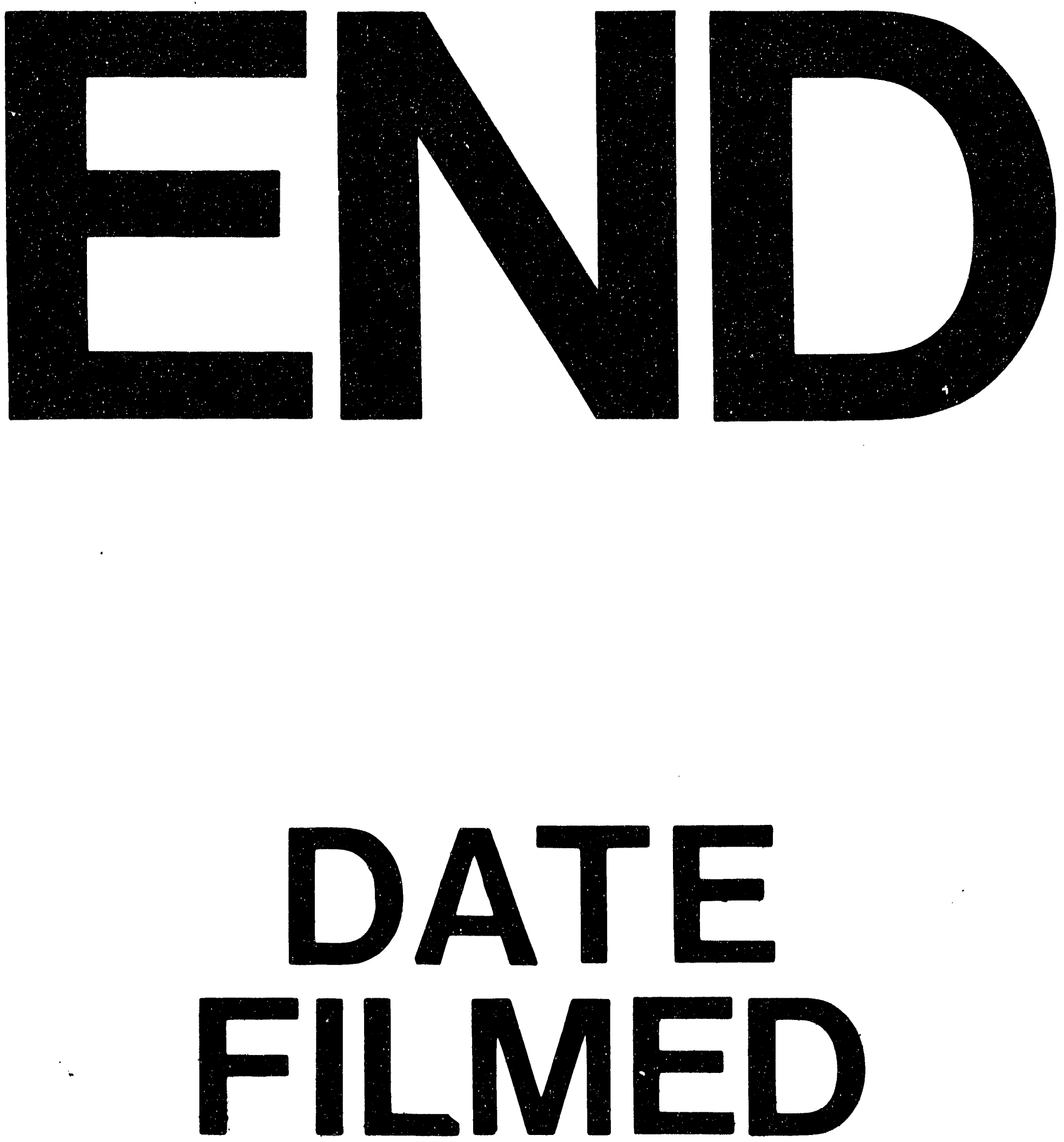

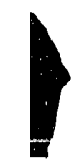
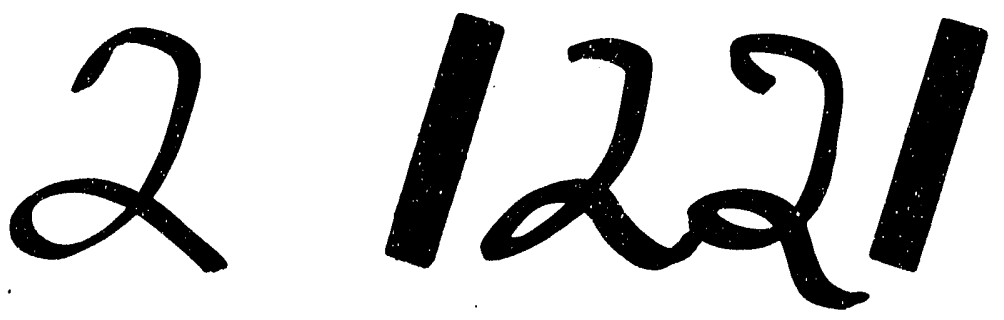

93 
